\title{
Transdermal Delivery of Rhizoma Coptidis and Evodia Rutaecarpa: The Effects of Enhancers on Permeation Across SD Mouse Skin
}

\section{Yu yao Guan}

Shandong Provincial Third Hosiptal, Cheeloo College of Medicine, Shandong University

\section{Xue mei Liu}

Shandong Provincial Third Hospital, Cheeloo College of Medicine, Shandong University

\section{Lei Zheng}

Shandong Provincial Third Hospital, Cheeloo College of Medicine, Shandong University

\section{Jing Yang}

Shandong University Cheeloo College of Medicine

Ji bo Ren

Shandong Qidu Pharmaceutical Co., Ltd

\section{Chao Song}

Shandong Provincial Third Hospital, Cheeloo College of Medicine, Shandong University

Xiao li Zhang

Shandong Provincial Third Hospital, Cheeloo College of Medicine, Shandong University

Jin qing Zhang ( $\nabla$ zjqing01@163.com )

Shandong University Cheeloo College of Medicine

\section{Research}

Keywords: enhancer, hairless mouse skin, rhizoma coptidis, evodia rutaecarpa, fat-soluble azone

Posted Date: November 19th, 2020

DOI: https://doi.org/10.21203/rs.3.rs-110148/v1

License: (1) (1) This work is licensed under a Creative Commons Attribution 4.0 International License. Read Full License 


\section{Abstract}

Background: Oral ulceration is a common, painful condition of uncertain aetiology. Traditional Chinese medicine has good effect. One kind of treatment method is to use rhizoma coptidis, evodia rutaecarpa powder $10 \mathrm{~g}$ each mixed with vinegar to paste in the foot springs point. The purpose of this study is to convert this prescription into a corresponding preparation for everyone's convenience.

Methods: The enhancement effect of a series of different concentrations of fat-soluble azone, watersoluble azone, dimethyl sulfoxides, acetic acid, on the skin permeability of rhizoma coptidis, evodia rutaecarpa powder was studied in vitro by using Franz diffusion cells and SD mouse skin. The concentrations of the main components palmatine hydrochloride, berberine hydrochloride, evodiamine, rutacarpine in the preparation were determined by an HPLC method.

Results: The addition of dimethyl sulfoxide, $2-8 \% \mathrm{w} / \mathrm{w}$ water-soluble azone, $8 \% \mathrm{w} / \mathrm{w}$ fat-soluble azone never increased palmatine hydrochloride and berberine hydrochloride flux with respect to the control preparation. The enhancing effects of $45 \%$ acetic acid, $1 \%$ water-soluble azone and $5 \%$ fat-soluble azone were evident on the palmatine hydrochloride and berberine hydrochloride permeability. The target substances evodiamine and rutacarpine were not detected in the receiving solution, and there were residues in the skin, respectively. The amount of evodiamine and rutacarpine residued in the skin obtained from formulations including $45 \% \mathrm{w} / \mathrm{w}$ acetic acid or $5 \% \mathrm{w} / \mathrm{w}$ fat-soluble azone were significantly higher $(p<0.05)$ than that obtained from the blank control formulation.

Conclusions: The experimental results revealed that $5 \%$ fat-soluble azone transdermal agent has the optimal performance in the rhizoma coptidis, evodia rutaecarpa preparation.

\section{Background}

Oral ulceration is a common, painful condition of uncertain aetiology with a general population prevalence exceeding $20 \%[1,2]$. Ulcers are characterised by immune-mediated mucosal destruction, inflammation, and a proliferative healing phase [3,4]. Usually they are self limiting, although they may be a recurrent problem in some people. Occasionally, oral ulcers may be a symptom of a more serious disease [5]. The management of oral ulcers is a challenge for clinicians. Whilst there is widespread use of topical corticosteroids [6-7], antibiotics [8] and antimicrobial [9], there is only weak evidence for the effectiveness of any of the topical treatments [10]. In China, traditional Chinese medicine treatment has achieved good curative effects [11]. As a public disease, oral ulceration has a high incidence in China [12]. Chinese clinicians have extensive experience in treating oral ulceration, conducting a large number of clinical trials. According to the theory of traditional Chinese medicine (TCM), the cause of this disease is heart and spleen heat, yin deficiency and fire, qi and blood deficiency, often using herbal and mineral medicine as common therapy [13]. In a meta-analysis published in 2015, the effect of topical Chinese medicine on recurrent oral ulcers was evaluated [11]. One kind of treatment method is to use rhizoma 
coptidis, evodia rutaecarpa powder $10 \mathrm{~g}$ each mixed with vinegar to paste in the foot springs point. The total effective rate was $90 \%[14,15]$.

Although the effect of this treatment method is better, there is no ready-made preparation and the operation is tedious. Patients need to buy the corresponding medicine, beaten into powder, mixed with vinegar into a paste. The purpose of this study is to convert this prescription into a corresponding preparation for everyone's convenience. However, vinegar is volatile, it is difficult to ensure the continuous transdermal promotion. In particular, the enhancement effect of a series of different concentrations of fat-soluble azone, water-soluble azone, dimethyl sulfoxides, acetic acid [16,17], on the skin permeability of rhizoma coptidis, evodia rutaecarpa powder was studied in vitro by using Franz diffusion cells and SD mouse skin, as a membrane. Compared with different concentrations of acetic acid, the most suitable transdermal absorbent was selected to prepare the preparation.

\section{Methods}

\section{Materials}

Rhizoma coptidis produced in Sichuan, evodia rutaecarpa produced in Henan were supplied by Jinan hebao traditional Chinese medicine co. LTD (China). Palmatine hydrochloride, berberine hydrochloride, evodiamine, rutacarpine were provided by Beijing solabao technology co. LTD (China). Fat-soluble azone, water-soluble azone of medical grade were obtained from Zhengzhou jinbei chemical industry co. LTD. Dimethyl sulfoxides of analytic grade was obtained from Tianjin kermiou chemical reagent co. LTD (China). Acetic acid of analytic grade was obtained from Tianjin guangfu technology development co. LTD (China). Acetonitrile, methanol were of high-performance liquid chromatography (HPLC) grade. Sodium dihydrogen phosphate, anhydrous formic acid were of analytic grade. $0.9 \%$ sodium chloride injection was of medical grade. The vinegar was of food grade.

\section{Paste Preparation}

Rhizoma coptidis and evodia rutaecarpa were crushed into powder and sifted through 100 mesh sieve. The main ingredients are rhizoma coptidis and evodia rutaecarpa powder with the mass ratio of 1:1. Then, the powder was made with $30-50 \% \mathrm{w} / \mathrm{w}$ dimethyl sulfoxides, $30-50 \% \mathrm{w} / \mathrm{w}$ acetic acid, $1-8 \% \mathrm{w} / \mathrm{w}$ water-soluble azone, $1-8 \% \mathrm{w} /$ wfat-soluble azone, $100 \%$ vinegar surfactants, excluding promoter to prepare the preparation. 28 kinds of preparation with different transdermal absorbents were made for external use only.

The effects of different transdermal absorbents on percutaneous administration of external preparations of rhizoma coptidis and evodia rutaecarpa were investigated by using cumulative penetration ratio and cumulative retention ratio as indexes.

\section{Skin Membrane Preparation}


Male SD mice, (Jinan, China), initial weight $140 \pm 10 \mathrm{~g}$, were used. The animals were housed in a conditioned environment $\left(21 \pm 2^{\circ} \mathrm{C}, 40-70 \%\right.$ relative humidity, 12-h light/12-h dark cycle), with free access to standard laboratory chow and tap water. The animal experiments are approved by Ethics Committee of the Hospital as Animal use project no. KYLL-201902. All animal experiments complied with the ARRIVE guidelines and were carried out in accordance the National Institutes of Health guide for the care and use of Laboratory animals (NIH Publications No. 8023, revised 1978). The mouse were sacrificed by dislocated neck. The full-thickness skin was excised from the abdominal site after removal of the fat and the subdermal tissues by surgical scissor. The skin was washed with saline solution, its integrity verified by means of visual inspection and then it was frozen at $-80^{\circ} \mathrm{C}$ until use.

\section{In Vitro Skin Permeation Study}

The SD mouse skin was carefully mounted on the lower half of the Franz cell with the dermis facing downwards and the stratum corneum side in contact with the preparation. The upper and lower parts of the Franz cell were fastened together by means of a clamp, with the membrane acting as a barrier between the donor and receptor compartments. The diffusion area and the volume of the receptor compartment are $1.131 \mathrm{~cm}^{2}$ and about $15 \mathrm{~mL}$, respectively. The receiver compartment was filled with a freshly prepared degassed saline. Special care was taken to avoid the formation of air bubbles between the solution and the membrane in the receptor compartment. The Franz cells were kept at $37 \pm 1^{\circ} \mathrm{C}$ throughout the experiment. Only the receptor compartment was in contact with the circulating water at $37^{\circ} \mathrm{C}$ and each Franz cell was equipped with a stirring magnet. At predetermined times, $5 \mathrm{~mL}$ samples were withdrawn at $2,4,6,8,10 \mathrm{~h}$ from the receiver compartment and immediately replaced with fresh receiver medium. Sink conditions were maintained throughout the experiment. The withdrawn samples were assayed directly by an HPLC method to determine the concentrations of the compound.

\section{In Vitro Skin Retention Study}

At the end of skin permeation experiments, the full-thickness hairless mouse skin was removed from the Franz cell and the plaster specimens were carefully eliminated. The skin was cut into pieces and placed in a $5 \mathrm{~mL}$ centrifuge tube. After $10 \mathrm{~min}$ of ultrasonic shaking with appropriate amount of methanol, methanol was transferred to a $5 \mathrm{~mL}$ volumetric flask, cleaned repeatedly with methanol and transferred to the volumetric flask. Methanol was then stabilized to the scale, shaken well, and filtered with $0.45 \mu \mathrm{m}$ microporous membrane.

\section{Permeation and Retention Parameters}

Permeation parameters were interpreted plotting cumulative penetration ratio and cumulative retention ratio.

$$
\mathrm{Qt} \%=\frac{M_{R 2} \times L_{R} \times V_{S} \times A_{S}}{V_{R} \times M_{S} \times A_{R 2}} \times 100 \%
$$

$\mathrm{Qn} \%=\sum_{2}^{n} \mathrm{Qt} \%$ 
$M_{R 2}$, the weight of the second reference $(\mathrm{mg}) . L_{R}$ the labeled content of the reference (\%). $V_{S}$, the volume of the receptor compartment $(15 \mathrm{~mL})$, the volume of constant volume $(5 \mathrm{~mL}) . A_{S}$, the peak area of the permeable or remaining active component in the sample. $V_{R}$ dilution volume of the reference $(5000 \mathrm{~mL}$ or $1000 \mathrm{~mL}) . M_{S}$ sample weight $(\mathrm{mg}) . A_{R 2}$, mean peak area of the second reference.

\section{HPLC Analysis}

The concentrations of the main components palmatine hydrochloride, berberine hydrochloride, evodiamine, rutacarpine in the preparation were determined by an HPLC method. The HPLC method was developed for the simultaneous determination of the four main components. The HPLC system used throughout this study was a Agilent 1260 HPLC, equipped with a Diode Array Detector.

The column was $\mathrm{C} 18,250 \times 4.6 \mathrm{~mm}, 5 \mu \mathrm{m}$ (Kromasil, Sweden) which was kept at $40^{\circ} \mathrm{C}$, with a specific precolumn. The mobile phase was $0.05 \mathrm{~mol} / \mathrm{L}$ sodium dihydrogen phosphate $(\mathrm{pH}=3.00) /$ acetonitrile $(49: 51 \%, v / v)$.

The flow rate was set to $1 \mathrm{~mL} / \mathrm{min}$. Six concentrations of the four standard compound were injected at 10 $\mu \mathrm{L}$ (the ranges for UV $261 \mathrm{~nm}$ detection are $0.05-10 \mu \mathrm{g} / \mathrm{mL}$ ). The linear regression equation of the standard curve, determinedin duplicate, was obtained by plotting the amount of the standard compound injected against the peak area.

\section{Results}

\section{In Vitro Skin Permeation Experiment: Influenceof different sieres of transdermal absorbent.}

The results of in vitro skin permeation experiment showed that the target substances, palmatine hydrochloride and berberine hydrochloride, were detected in the receiving solution, while evodiamine and rutacarpine were not detected.

The palmatine hydrochloride and berberine hydrochloride skin permeation profiles of the rhizoma coptidis, evodia rutaecarpa preparation were linear. The palmatine hydrochloride and berberine hydrochloride permeation profiles obtained by the rhizoma coptidis, evodia rutaecarpa preparation containing $30-50 \% \mathrm{w} / \mathrm{w}$ dimethyl sulfoxides, $30-50 \% \mathrm{w} /$ wacetic acid, $1-8 \% \mathrm{w} / \mathrm{w}$ water-soluble azone, 1$8 \% \mathrm{w} /$ wfat-soluble azone, $100 \%$ vinegar surfactants and blank control were linear and reported in Fig. 1-8.

In their respective series, $50 \%$ dimethyl sulfoxide, $45 \%$ acetic acid, $1 \%$ water-soluble azone and $5 \%$ fatsoluble azone had the best skin penetration effects for palmatine hydrochloride and berberine hydrochloride. The palmatine hydrochloride and berberine hydrochloride permeation profiles of transdermal promoter with best skin penetration effects in their respective series were reported in Fig. 910. The cumulative penetration ratio were reported in Table I.

The addition of dimethyl sulfoxide, $2-8 \% \mathrm{w} / \mathrm{w}$ water-soluble azone, $8 \% \mathrm{w} / \mathrm{w}$ fat-soluble azone never increased palmatine hydrochloride and berberine hydrochloride flux with respect to the control 
preparation.

The palmatine hydrochloride and berberine hydrochloride cumulative penetration ratio obtained from formulations including $30-50 \% \mathrm{w} / \mathrm{w}$ acetic acid, $1 \% \mathrm{w} / \mathrm{w}$ water-soluble azone or $1-7 \% \mathrm{w} / \mathrm{w}$ fat-soluble azone were significantly higher $(\mathrm{p}<0.05)$ than that obtained from the blank control formulation. Moreover, the palmatine hydrochloride and berberine hydrochloride cumulative penetration ratio nonlinearly increased according to the amount of enhancer loaded in the preparation.

Generally speaking, the permeated amounts of palmatine hydrochloride and berberine hydrochloride were obviously increased and the enhancing effects of $45 \%$ acetic acid, $1 \%$ water-soluble azone and $5 \%$ fatsoluble azone were evident on the palmatine hydrochloride and berberine hydrochloride permeability (Table I).

In order to verify the skin permeation of evodiamine and rutacarpine with traditional vinegar as transdermal promoter, the in vitro skin permeation experiment was carried out. The results showed that the target substances evodiamine and rutacarpine were not detected in the receiving solution, and there were residues in the skin, respectively.

The preparation containing $45 \% \mathrm{w} / \mathrm{w}$ acetic acid, $1 \% \mathrm{w} / \mathrm{w}$ water-soluble azone, $5 \% \mathrm{w} / \mathrm{w}$ fat-soluble azone, $100 \% \mathrm{w} / \mathrm{w}$ vinegar surfactants and the blank control were tested the residues in the skin. The data are reported in Table II.

The addition of $1 \% \mathrm{w} / \mathrm{w}$ water-soluble azone never increased the residued amount of evodiamine and rutacarpine in the skin with respect to the control preparation.

The amount of evodiamine and rutacarpine residued in the skin obtained from formulations including $45 \% \mathrm{w} / \mathrm{w}$ acetic acid or $5 \% \mathrm{w} / \mathrm{w}$ fat-soluble azone were significantly higher $(\mathrm{p}<0.05)$ than that obtained from the blank control formulation.

\section{Discussion}

The current results underlined the effects of different transdermal promoters on transdermal administration of rhizoma coptidis and evodia rutaecarpa. Acetic acid, fat-soluble azone, water-soluble azone were able to promote the skin penetration of palmatine hydrochloride and berberine hydrochloride according to its concentrations in the preparation. Dimethyl sulfoxide, vinegar were unable to promote the skin penetration.

In different series of promoters, $45 \%$ acetic acid, $50 \%$ dimethyl sulfoxide, $5 \%$ fat-soluble azone and $1 \%$ water-soluble azone had the best effect on the penetration of palmatine hydrochloride and berberine hydrochloride in their respective series. However, the penetration effect of $50 \%$ dimethyl sulfoxide and vinegar in traditional prescription was worse than that in blank control. 
As to penetration of palmatine hydrochloride, the effect of the enhancers was in the order $45 \%$ acetic acid ( 2.30 -fold $)>5 \% \mathrm{w} / \mathrm{w}$ fat-soluble azone $(1.90$-fold $)>1 \% \mathrm{w} / \mathrm{w}$ water-soluble azone ( 1.68 -fold $)>$ blank control $>50 \%$ dimethyl sulfoxide( 1.34 -fold $)>100 \%$ vinegar( 3.15 -fold $)$.

As to penetration of berberine hydrochloride, the effect of the enhancers was in the order $45 \%$ acetic acid (2.56-fold) $>5 \% \mathrm{w} / \mathrm{w}$ fat-soluble azone (2.32-fold) $>1 \% \mathrm{w} / \mathrm{w}$ water-soluble azone (1.82-fold) $>$ blank control $>50 \%$ dimethyl sulfoxide( 1.12 -fold $)>100 \% \operatorname{vinegar}(2.10$-fold $)$.

In accordance with literature data, evodiamine and rutacarpine were not detected in the receiving solution but residued in the skin[18].

As to retention of evodiamine, the effect of the enhancers was in the order $45 \%$ acetic acid (4.62fold) $>100 \%$ vinegar( 4.48 -fold $)>5 \% \mathrm{w} / \mathrm{w}$ fat-soluble azone $(2.24$-fold) $\mid>$ blank control $>1 \% \mathrm{w} / \mathrm{w}$ water-soluble azone (1.29-fold).

As to retention of rutacarpine, the effect of the enhancers was in the order $45 \%$ acetic acid (2.89fold $)>100 \%$ vinegar( 2.14 -fold $)>5 \% \mathrm{w} / \mathrm{w}$ fat-soluble azone $(1.82$-fold $)$ I $>$ blank control $=1 \% \mathrm{w} / \mathrm{w}$ water-soluble azone.

$5 \%$ fat-soluble azone transdermal agent has the optimal performance in the rhizoma coptidis and evodia rutaecarpa preparation.

\section{Conclusions}

For rhizoma coptidis, evodia rutaecarpa preparation for external use only, the transdermal effects of different concentrations of fat-soluble azone, water-soluble azone and dimethyl sulfoxide were compared with that of acetic acid $45 \%$ concentration which had the best penetrating effect. $1 \%$ water-soluble azone and $5 \%$ fat-soluble azone had the similar penetrating effect as $45 \%$ acetic acid.

The two components of evodiamine and rutacarpine did not penetrate the skin but remained in the skin. For $4 \%-6 \%$ fat-soluble azone and $45 \%$ acetic acid with good transdermal effect, they were respectively tested for retention of evodiamine and rutacarpine in the skin after $10 \mathrm{~h}$ transmission. Retention was highest at $45 \%$ acetic acid concentration. $5 \%$ fat-soluble azone was comparable.

The preparation of rhizoma coptidis, evodia rutaecarpa with $5 \%$ fat-soluble azone as transdermal promoter will be a potential candidate drug for the treatment of oral ulcer.

\section{Abbreviations}

SD mouse: Sprague-Dawley mouse; HPLC: high performance liquid chromatography ; TCM: traditional Chinese medicine; co. LTD: company limited; NIH: National Institutes of Health; UV: ultraviolet.

\section{Declarations}




\section{Ethics approval and consent to participate}

The animal experiments are approved by Ethics Committee of the Hospital as Animal use project no. KYLL-201902. Not applicable for consent to participate.

\section{Consent for publication}

All authors have provided consent for publication in the journal of Chinese Medicine.

\section{Availability of data and materials}

The materials and data of this study are available to other researchers upon request.

\section{Competing interests}

The authors declare that they have no competing interests.

\section{Funding}

This work was supported by the Key projects of China Pharmaceutical Association for promoting the dissemination of precision medicine science and technology (grant no. CMEI2019KPYJ (JZYY)00204), the Science and Technology development plan of Traditional Chinese Medicine of Health Commission of Shandong

Province (grant no. 2017-284), the Medical and Health Science and Technology development plan of Shandong Province (grant no. 2017WS473), the Science and Technology development plan of Traditional Chinese Medicine of Health Commission of Shandong Province (grant no. 2019-0329), and the Special Fund for clinical Research of Shandong Provincial Medical Association (grant no. YXH2019ZX016).

\section{Authors' contributions}

YYG, XML and JQZ were involved in conception and design of the study, data analysis, and preparation of the manuscript. LZ, JY and JBR were responsible for establishing a detection method and data analysis. CS and XLZ were responsible for permeation experiments and data analysis. All authors read and approved the final manuscript.

\section{Acknowledgements}

Not applicable.

\section{Author details}

${ }^{1}$ Department of Pharmacy, Shandong Provincial Third Hospital, Cheeloo College of Medicine, Shandong University, 11 Wuyingshan Road, Jinan 250031, Shandong, China. ${ }^{2}$ Shandong Qidu Pharmaceutical Co.,Ltd., 17 Hongda Road, Zibo 255400, Shandong, China. ${ }^{3}$ Department of Breast and Thyroid surgery, Shandong Provincial Third Hospital, Cheeloo College of Medicine, Shandong University, 11 Wuyingshan Road, Jinan 250031, Shandong, China. 


\section{References}

1. Haworth S, Haycock P, West N, Thomas SJ, Franks P, Timpson N. Gene discovery for oral ulceration: a UK Biobank Study. Lancet 2017; 389(1):46-46.

2. Abdulrab S, Halboub E, Barngkge I, Al-hebshi N-Acetylcysteine as a Candidate Therapeutic for Recurrent Aphthous and Aphthous-Like Ulcers. Dental Hypotheses2017; 8(1):17-22.

3. VaillantL, Samimi Aphthous Ulcers and Oral Ulcerations. Presse Med. 2016;45(2):215-226.

4. Fitzpatrick SG, Cohen DM, Clark AN.Ulcerated Lesions of the Oral Mucosa: Clinical and Histologic Review. Head Neck Pathol. 2019;13(1):91-102.

5. Bruce AJ, Dabade TS, Burkemper NM.Diagnosing Oral Ulcers. 2015;28(2):1-10.

6. Fantozzi PJ, Treister N, Shekar R, Woo SB, Villa A. Intralesional Triamcinolone Acetonide Therapy for Inflammatory Oral Ulcers. Oral Surg Oral Med Oral Pathol Oral Radiol. 2019;128(5):485-490.

7. Otero-ReyEM, Suarez-Alen F, Peñamaria-Mallon M, Lopez-Lopez J, Blanco-Carrion Malignant transformation of oral lichen planus by a chronic inflammatory process. Use of topical corticosteroids to prevent this progression?. Acta Odontol Scand. 2014;72(8):570-577.

8. Altenburg A, El-Haj N, Micheli C, Puttkammer M, Abdel-Naser MB, Zouboulis CC. The Treatment of Chronic Recurrent Oral Aphthous Ulcers. Dtsch Arztebl Int. 2014;111(40):665-673.

9. Casale M, Moffa A, Vella P, Rinaldi V, Lopez MA, Grimaldi V, Salvinelli F.Systematic Review: The Efficacy of Topical Hyaluronic Acid on Oral Ulcers. J Biol Regul Homeost Agents. 2017;31(4 Suppl 2):63-69.

10. Schemel-SuárezM, López-López J, Chimenos-Küstner Oral Ulcers: Differential Diagnosis and Treatment. Med Clin (Barc). 2015;145(11):499-503.

11. Li CL, Huang HL, Wang WC, et al. Efficacy and safety of topical herbal medicine treatment on recurrent aphthous stomatitis: a systemic review.Drug Des Devel Ther 2016;10:107-15.

12. Liu J, Zeng X, Chen $Q$, et al. An evaluation on the efficacy and safety ofamlexanox oral adhesive tablets in the treatment of recurrent minoraphthous ulceration in a Chinese cohort: a randomized, double-blind,vehicle-controlled, unparallel multicenter clinical trial. Oral Surg Oral Med Oral Pathol Oral Radiol Endod 2006;102:475-81.

13. O'Brien KA, Xue CC. The Theoretical Framework of Chinese Medicine.A Comprehensive Guide to Chinese Medicine:29-66.

14. Li H. Treatment of Recurrent Aral Uicers by Traditional Chinese Medicine. World Latest Medicine Information (Electronic Version). 2018;18(72): 71-73.

15. Zhang YH. Observation oncurative effect of Yongquan acupoint external applying of medicinal evodia fruit and figwortflower picrorhiza rhizome to treat children with dental ulcer and nursing care of them. Chinese Nursing Research. 2007; 21(1C): 242-243.

16. Hu XG, DuJL, An N, ZhaoJH. Application progress of passive and active penetration enhancement techniques in transdermal delivery of Chinese medicine. Academic Journal of Shanghai University of 
Traditional Chinese Medicine. 2019; 33(3): 93-96.

17. Chen HF, Wu QG, Hu YQ. Research progress of transdermal delivery preparation of Traditional Chinese medicine. Journal of Guangxi University of Chinese Medicine. 2017; 20(1): 69-72.

18. Zhao Q, Zhang RT, ZhangJW, Wang QW, Qiao YG, Zhao CB, Song YJ, Yang B, Tan YX. In Vitro Percutaneous Absorption of Fructus Evodiae Powder and Its Main Active Ingredients. Acta Chinese Medicne. 2019; 34(255): 1730-1734.

\section{Tables}

Table I. Skin cumulative penetration ratio of palmatine hydrochloride and berberine hydrochloride

\begin{tabular}{|lllllll|}
\hline $\begin{array}{l}\text { cumulative } \\
\text { penetration ratio }\end{array}$ & $\begin{array}{l}\text { acetic } \\
\text { acid } \\
45 \%\end{array}$ & $\begin{array}{l}\text { dimethyl } \\
\text { sulfoxide } \\
50 \%\end{array}$ & $\begin{array}{l}\text { water-soluble } \\
\text { azone 1\% }\end{array}$ & $\begin{array}{l}\text { fat-soluble } \\
\text { azone } 5 \%\end{array}$ & $\begin{array}{l}\text { vinegar } \\
100 \%\end{array}$ & $\begin{array}{l}\text { blank } \\
\text { control }\end{array}$ \\
\hline $\begin{array}{l}\text { barmatine } \\
\text { hydrochloride }\end{array}$ & $0.1965 \%$ & $0.0639 \%$ & $0.1436 \%$ & $0.1628 \%$ & $0.0271 \%$ & $0.0854 \%$ \\
\hline $\begin{array}{l}\text { berberine } \\
\text { hydrochloride }\end{array}$ & $0.5952 \%$ & $0.2058 \%$ & $0.4207 \%$ & $0.5370 \%$ & $0.1103 \%$ & $0.2311 \%$ \\
\hline
\end{tabular}

Table II. Skin cumulative retention ratio of evodiamine and rutacarpine

\begin{tabular}{|llllll|}
\hline $\begin{array}{l}\text { cumulative } \\
\text { retention ratio }\end{array}$ & $\begin{array}{l}\text { acetic acid } \\
45 \%\end{array}$ & $\begin{array}{l}\text { water-soluble } \\
\text { azone 1\% }\end{array}$ & $\begin{array}{l}\text { fat-soluble } \\
\text { azone 5\% }\end{array}$ & $\begin{array}{l}\text { vinegar } \\
100 \%\end{array}$ & $\begin{array}{l}\text { blank } \\
\text { control }\end{array}$ \\
\hline evodiamine & $0.0152 \%$ & $0.0026 \%$ & $0.0074 \%$ & $0.0148 \%$ & $0.0033 \%$ \\
\hline rutacarpine & $0.0106 \%$ & $0.0037 \%$ & $0.0067 \%$ & $0.0079 \%$ & $0.0037 \%$ \\
\hline
\end{tabular}

\section{Figures}




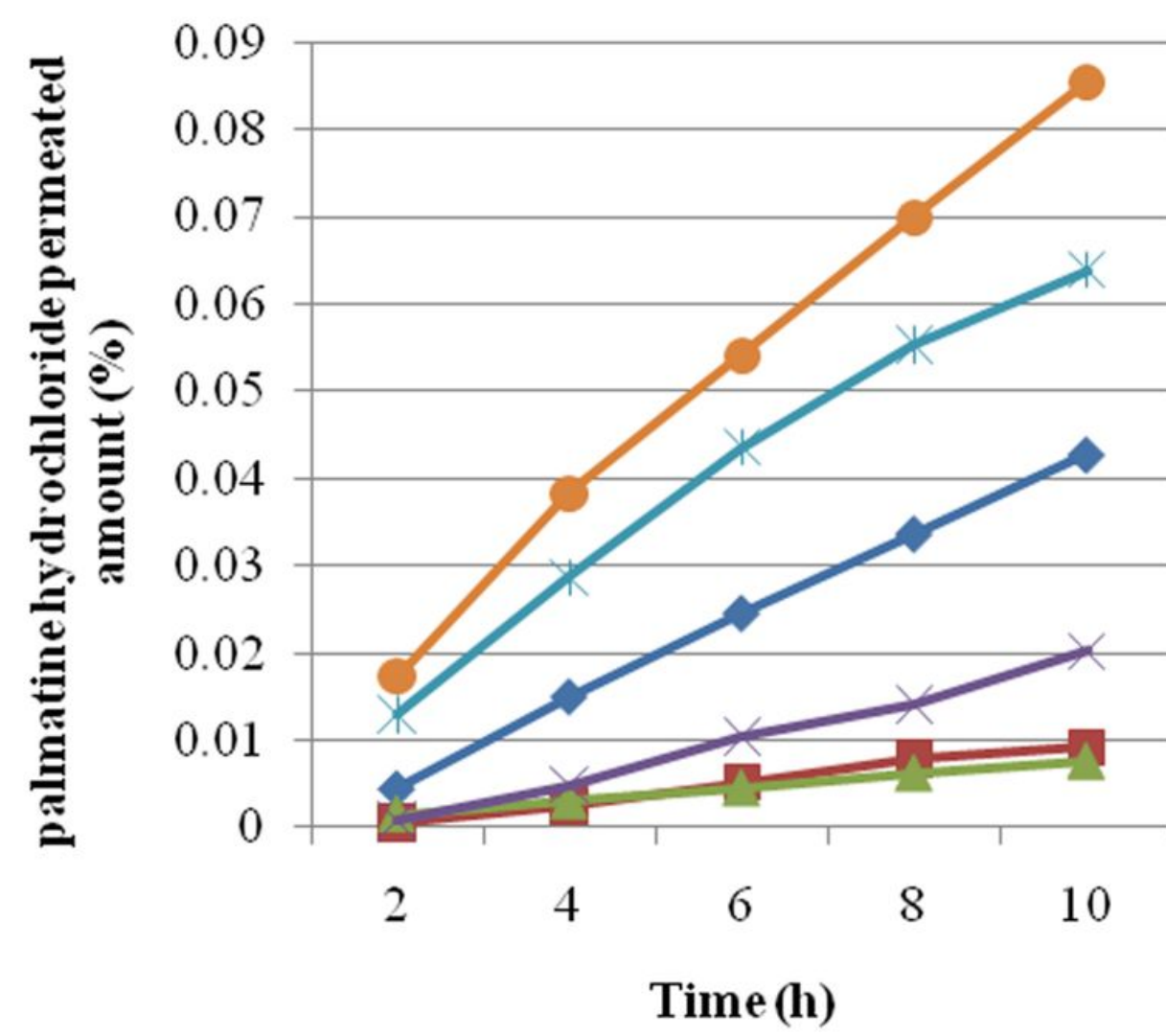

—dimethyl sulfoxide $30 \%$

- - dimethyl sulfoxide $35 \%$

- dimethyl sulfoxide $40 \%$

$\longleftarrow$ dimethyl sulfoxide $45 \%$

- dimethyl sulfoxide $50 \%$ blank control

\section{Figure 1}

Permeation profiles of palmatine hydrochloride in plasters containing $30-50 \% \mathrm{w} / \mathrm{w}$ dimethyl sulfoxide 


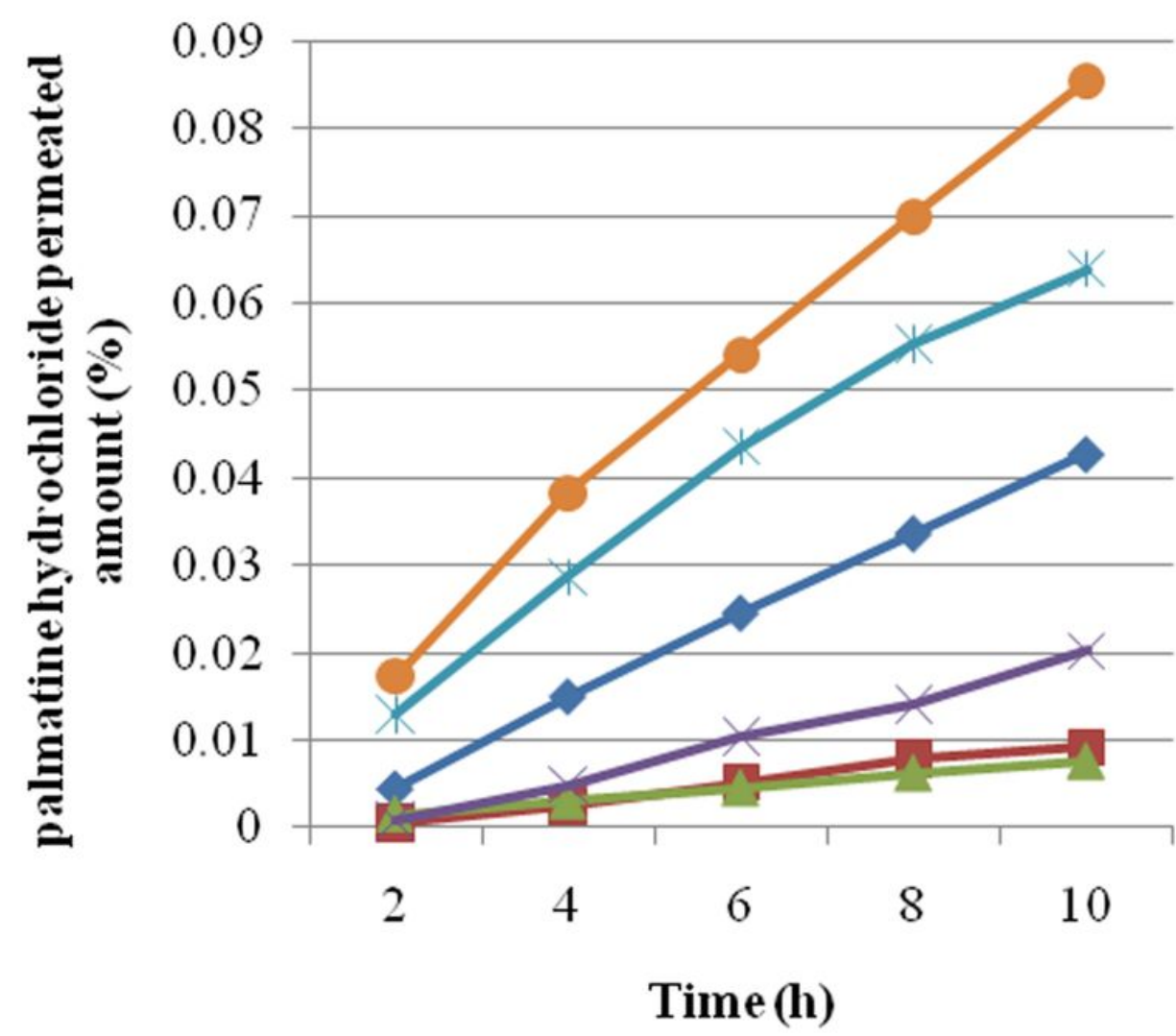

$\smile$ dimethyl sulfoxide $30 \%$

- dimethyl sulfoxide $35 \%$

- dimethyl sulfoxide $40 \%$

$\longleftarrow$ dimethyl sulfoxide $45 \%$

* dimethyl sulfoxide $50 \%$ blank control

\section{Figure 1}

Permeation profiles of palmatine hydrochloride in plasters containing $30-50 \% \mathrm{w} / \mathrm{w}$ dimethyl sulfoxide 


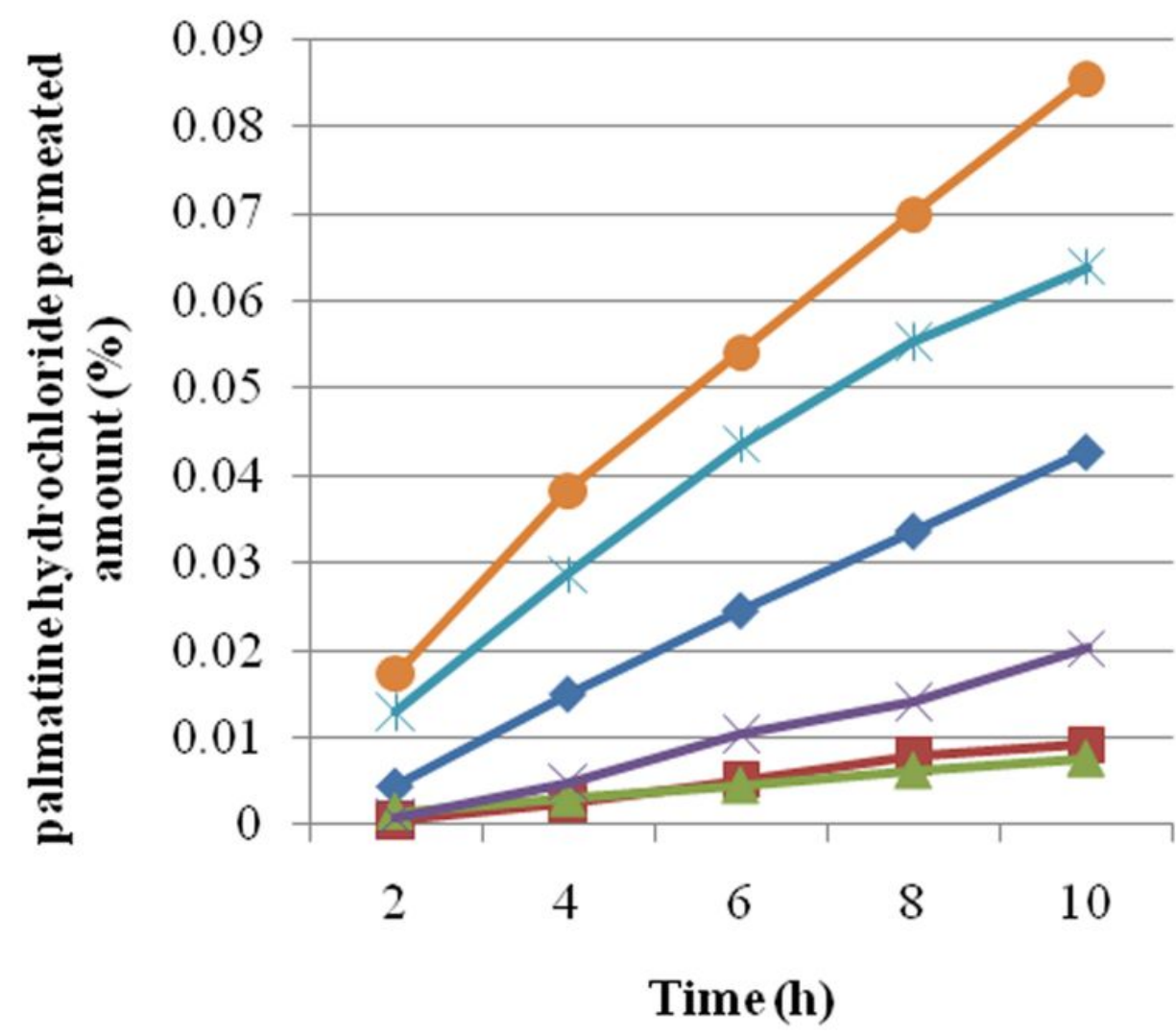

$\multimap$ dimethyl sulfoxide $30 \%$

- - dimethyl sulfoxide $35 \%$

- dimethyl sulfoxide $40 \%$

$\leftarrow$ dimethyl sulfoxide $45 \%$

* dimethyl sulfoxide $50 \%$ blank control

\section{Figure 1}

Permeation profiles of palmatine hydrochloride in plasters containing $30-50 \% \mathrm{w} / \mathrm{w}$ dimethyl sulfoxide 


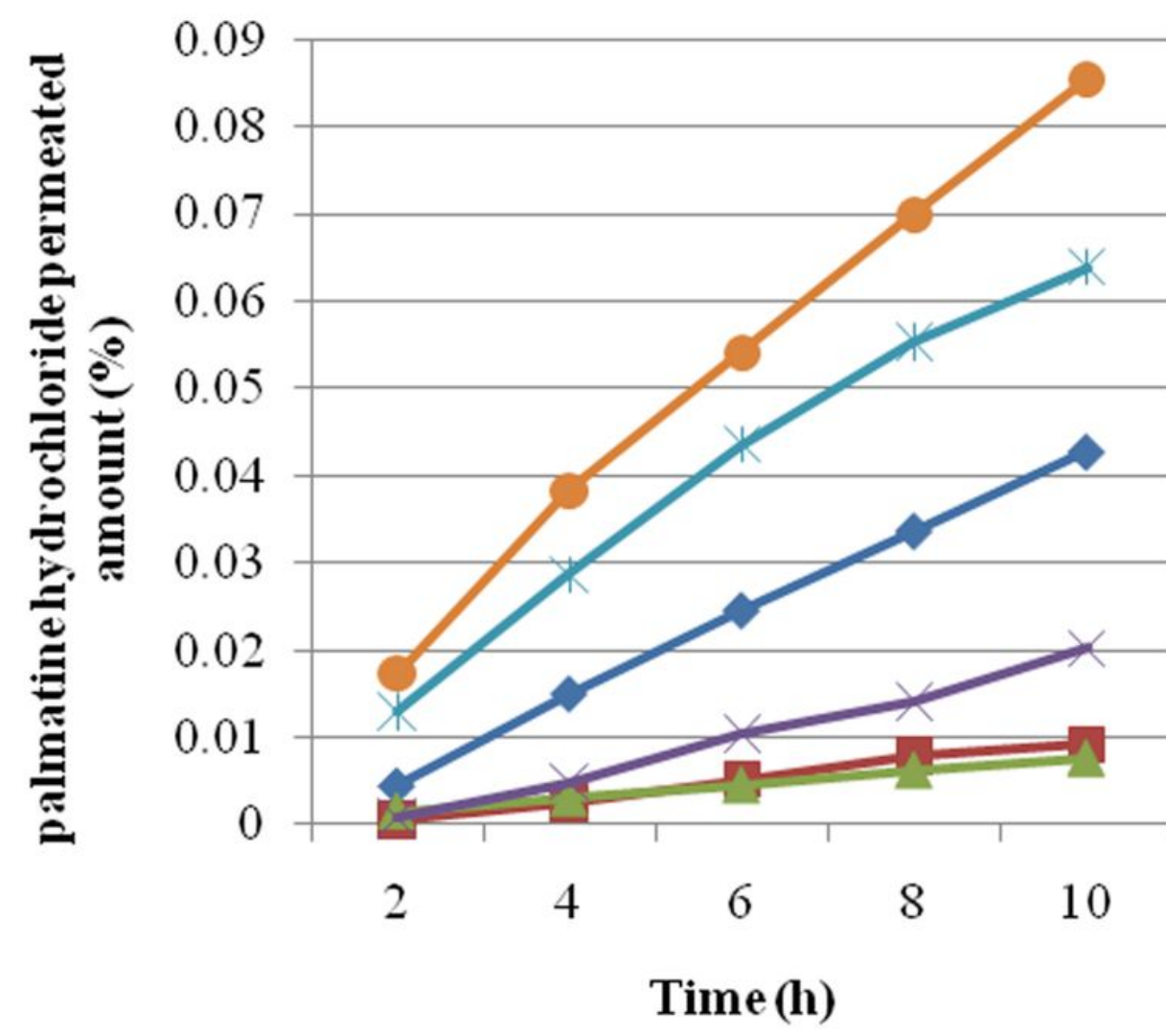

—dimethyl sulfoxide $30 \%$

- - dimethyl sulfoxide $35 \%$

- dimethyl sulfoxide $40 \%$

$\longleftarrow$ dimethyl sulfoxide $45 \%$

- dimethyl sulfoxide $50 \%$ blank control

\section{Figure 1}

Permeation profiles of palmatine hydrochloride in plasters containing $30-50 \% \mathrm{w} / \mathrm{w}$ dimethyl sulfoxide 


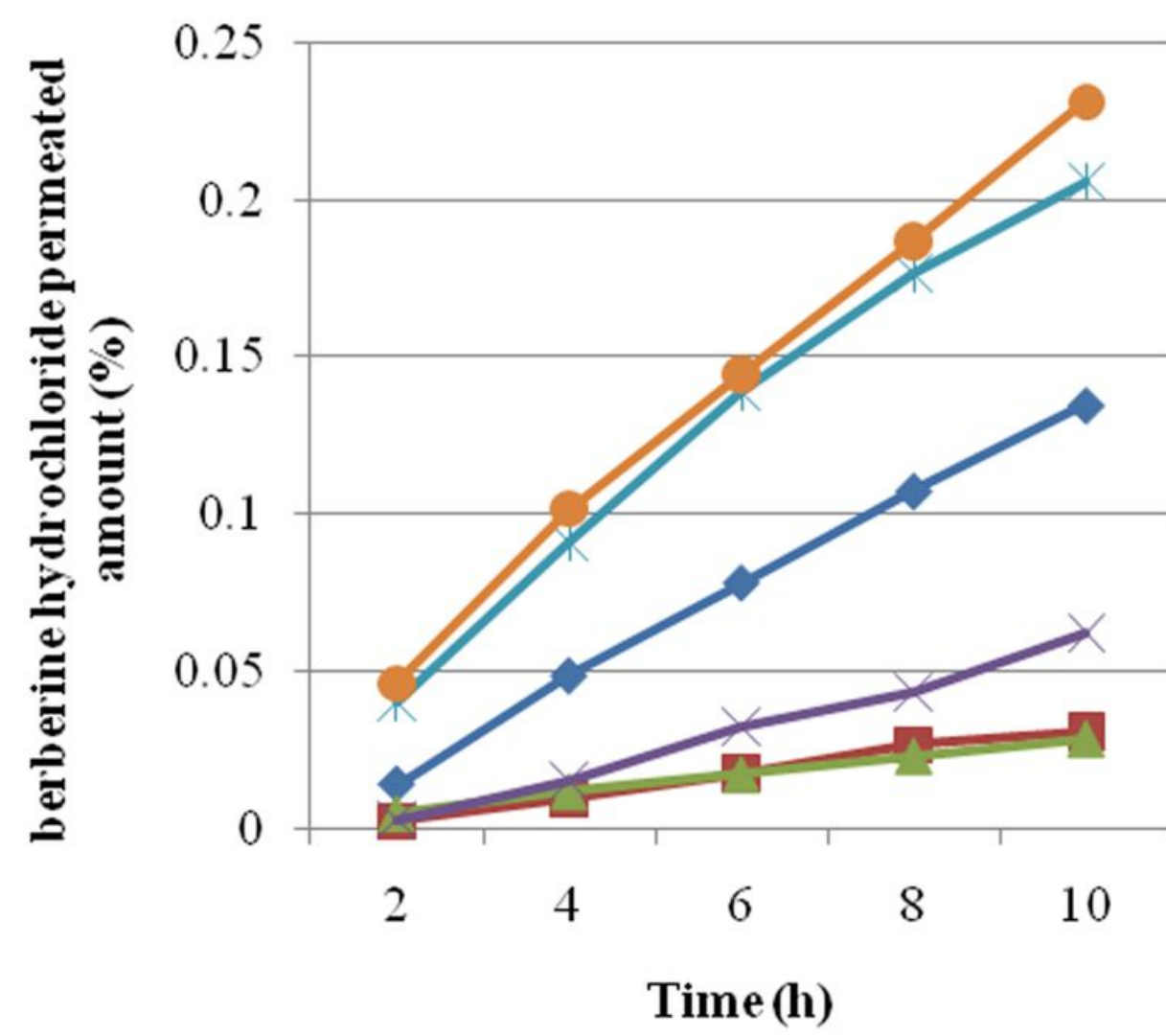

$\multimap$ dimethyl sulfoxide $30 \%$

-Cdimethyl sulfoxide $35 \%$

- dimethyl sulfoxide $40 \%$

$\leftarrow$ dimethyl sulfoxide $45 \%$

- dimethyl sulfoxide $50 \%$ blank control

Figure 2

Permeation profiles of berberine hydrochloride in plasters containing $30-50 \% \mathrm{w} / \mathrm{w}$ dimethyl sulfoxide 


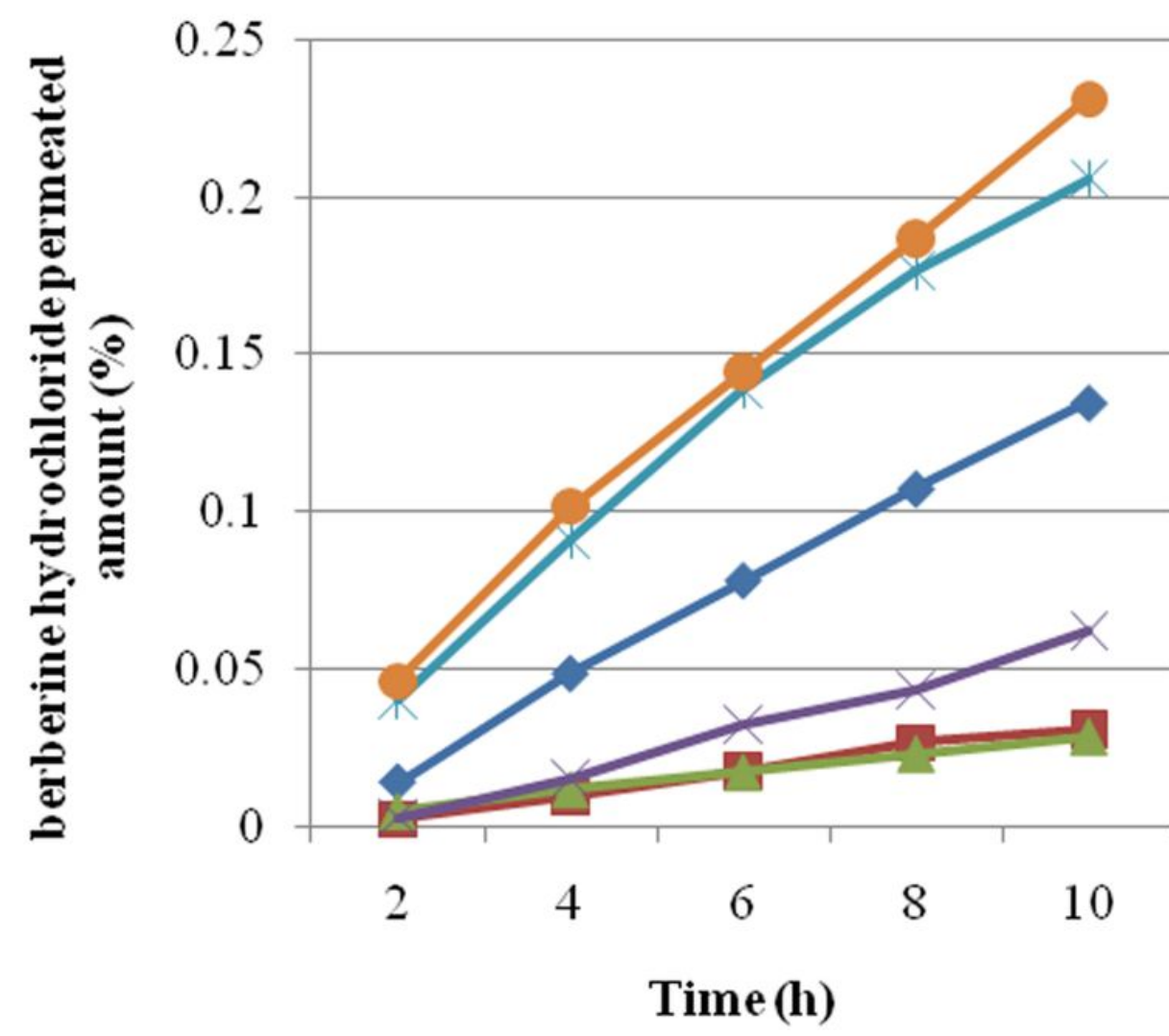

—dimethyl sulfoxide $30 \%$

- -dimethyl sulfoxide $35 \%$

- dimethyl sulfoxide $40 \%$

$\leftarrow$ dimethyl sulfoxide $45 \%$

- dimethyl sulfoxide $50 \%$ blank control

Figure 2

Permeation profiles of berberine hydrochloride in plasters containing $30-50 \% \mathrm{w} / \mathrm{w}$ dimethyl sulfoxide 


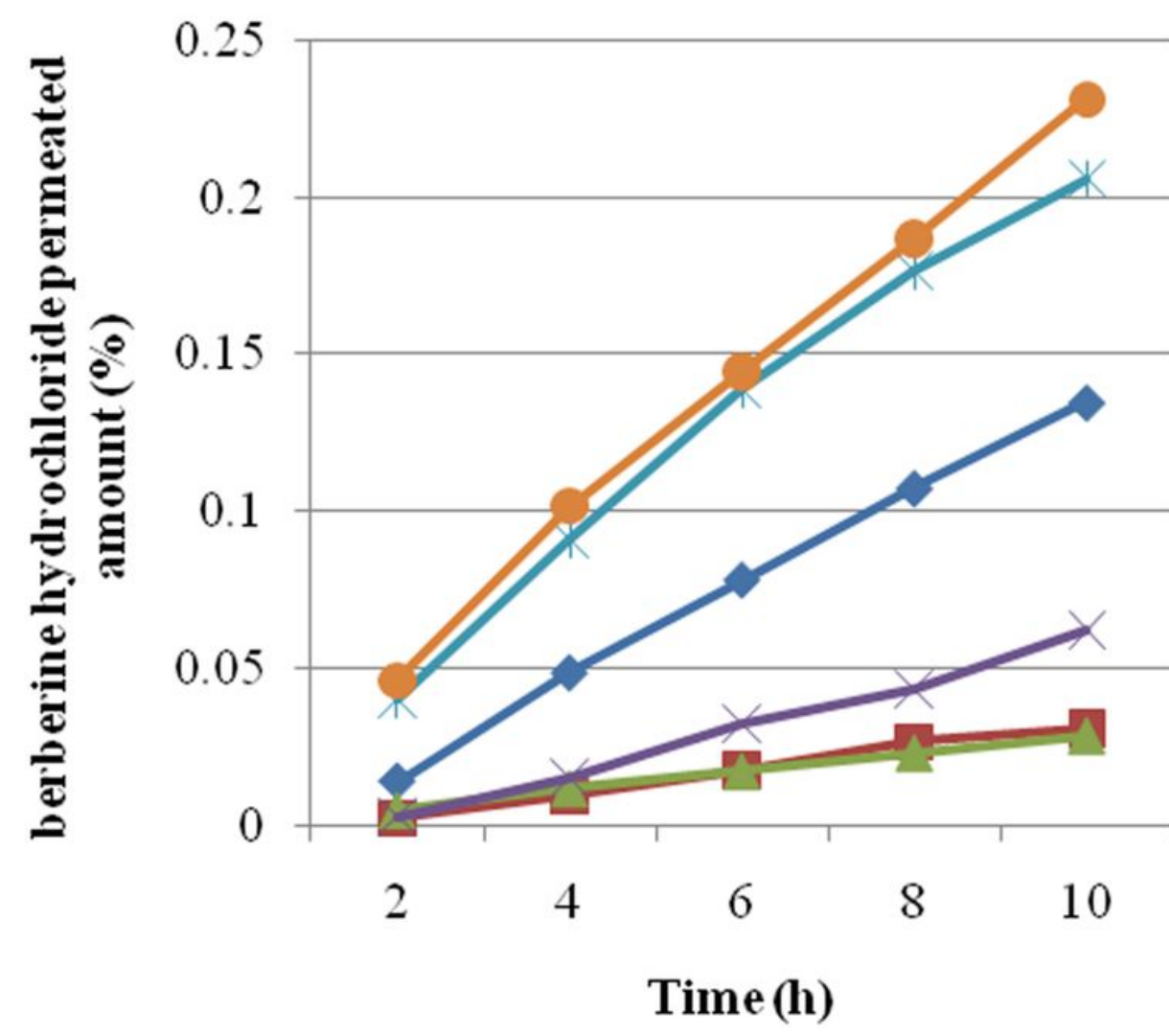

$\multimap$ dimethyl sulfoxide $30 \%$

-Cdimethyl sulfoxide $35 \%$

- dimethyl sulfoxide $40 \%$

$\leftarrow$ dimethyl sulfoxide $45 \%$

* dimethyl sulfoxide $50 \%$ blank control

Figure 2

Permeation profiles of berberine hydrochloride in plasters containing $30-50 \% \mathrm{w} / \mathrm{w}$ dimethyl sulfoxide 


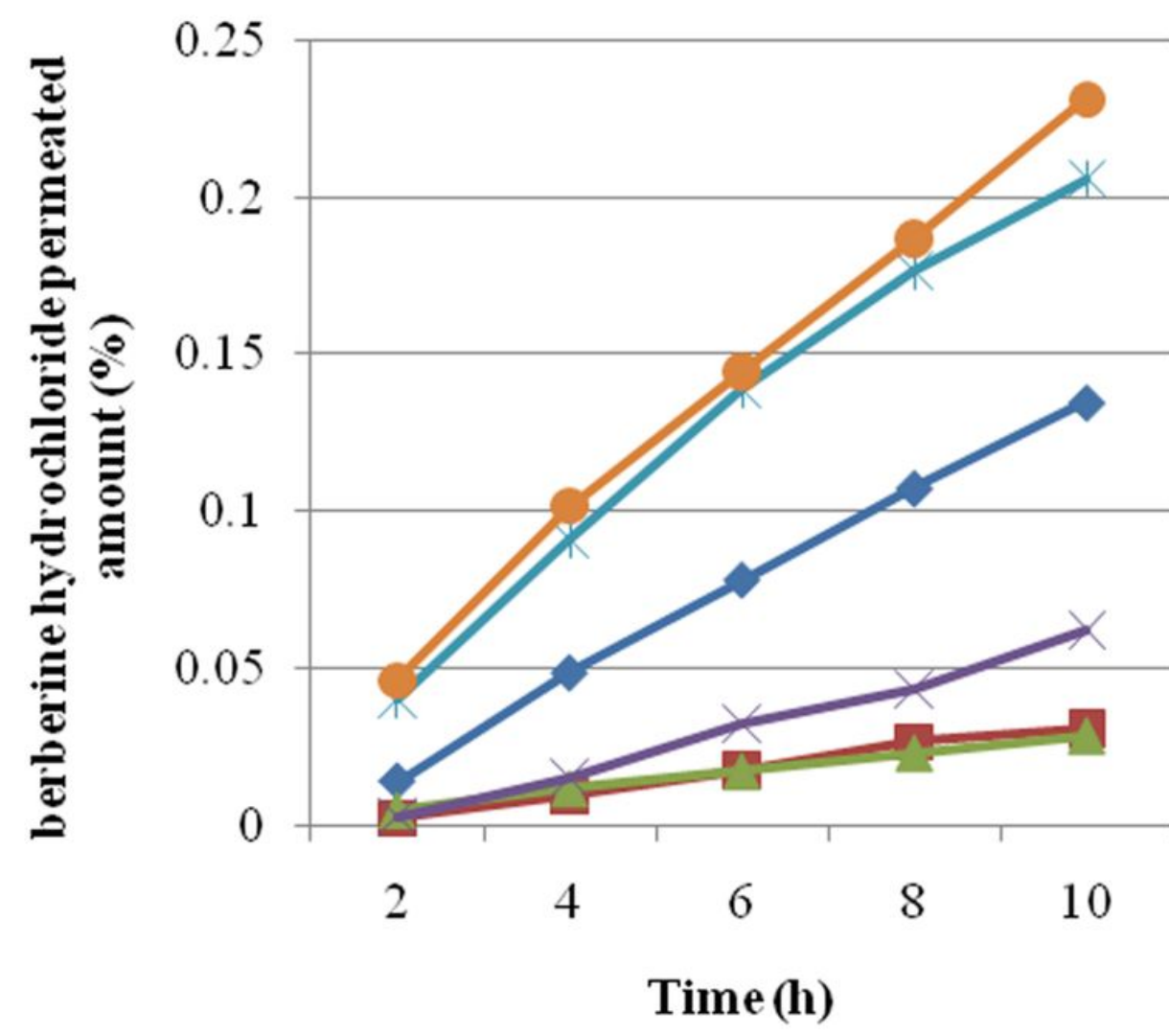

$\multimap$ dimethyl sulfoxide $30 \%$

-Cdimethyl sulfoxide $35 \%$

- dimethyl sulfoxide $40 \%$

$\leftarrow$ dimethyl sulfoxide $45 \%$

* dimethyl sulfoxide $50 \%$ blank control

Figure 2

Permeation profiles of berberine hydrochloride in plasters containing $30-50 \% \mathrm{w} / \mathrm{w}$ dimethyl sulfoxide 


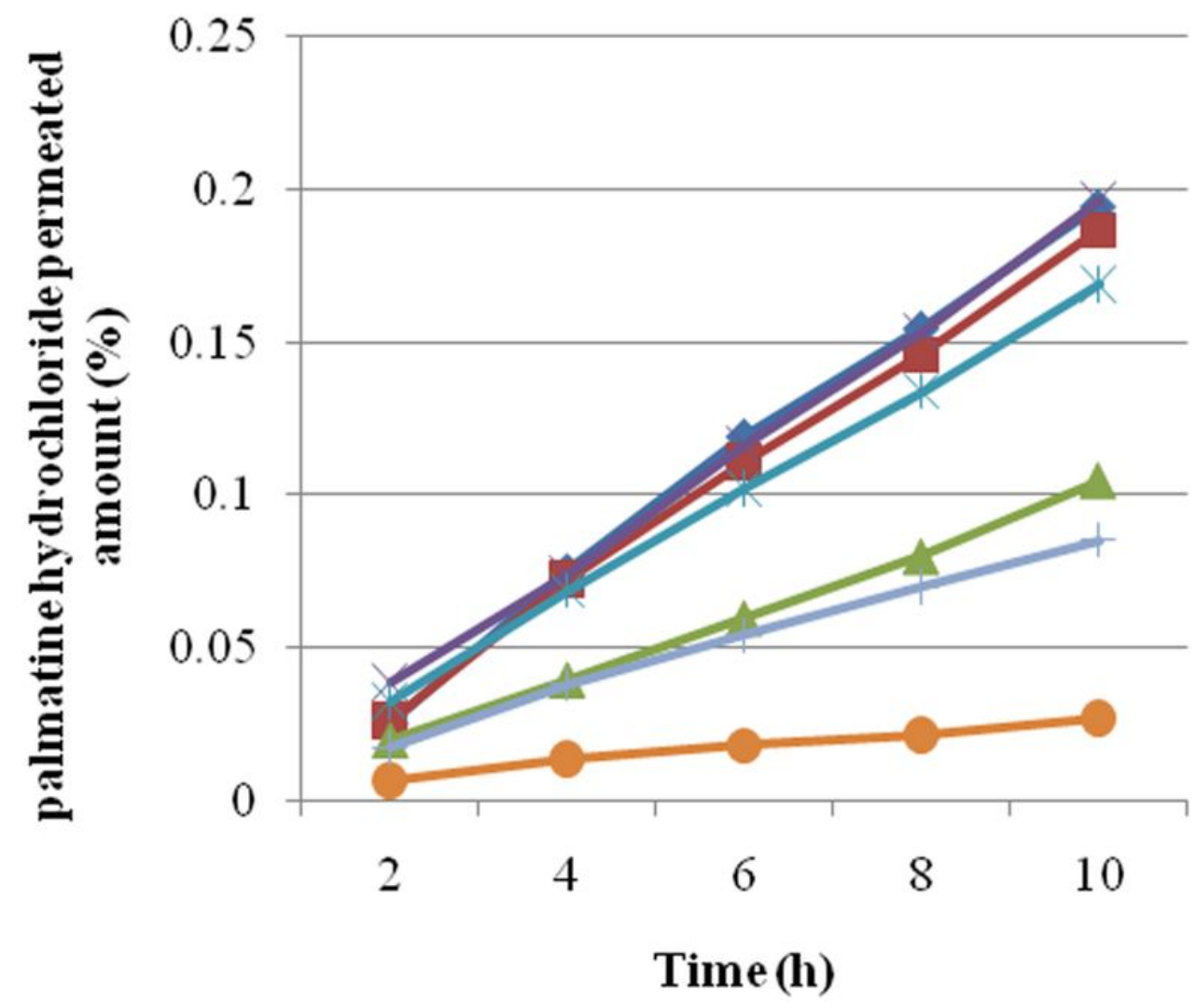

- acetic acid $30 \%$

- - acetic acid $35 \%$

- acetic acid $40 \%$

$\longleftarrow$ acetic acid $45 \%$

* acetic acid $50 \%$

— vinegar $100 \%$

+ blank control

\section{Figure 3}

Permeation profiles of palmatine hydrochloride in plasters containing $30-50 \% \mathrm{w} / \mathrm{w}$ acetic acid 


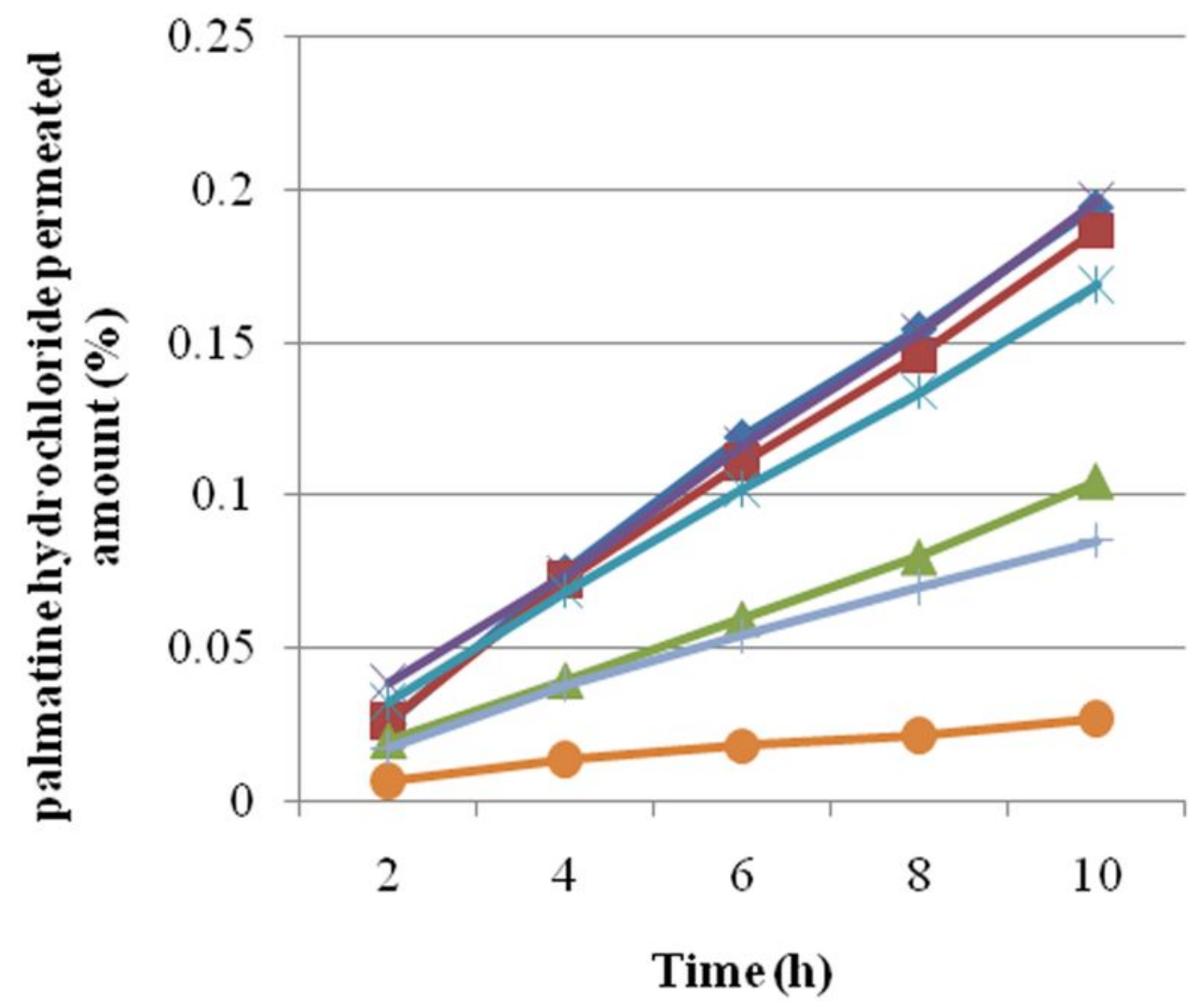

$\longrightarrow$ acetic acid $30 \%$

- acetic acid $35 \%$

- acetic acid $40 \%$

$\longleftarrow$ acetic acid $45 \%$

* acetic acid $50 \%$

- vinegar $100 \%$

$\longrightarrow$ blank control

\section{Figure 3}

Permeation profiles of palmatine hydrochloride in plasters containing $30-50 \% \mathrm{w} / \mathrm{w}$ acetic acid 


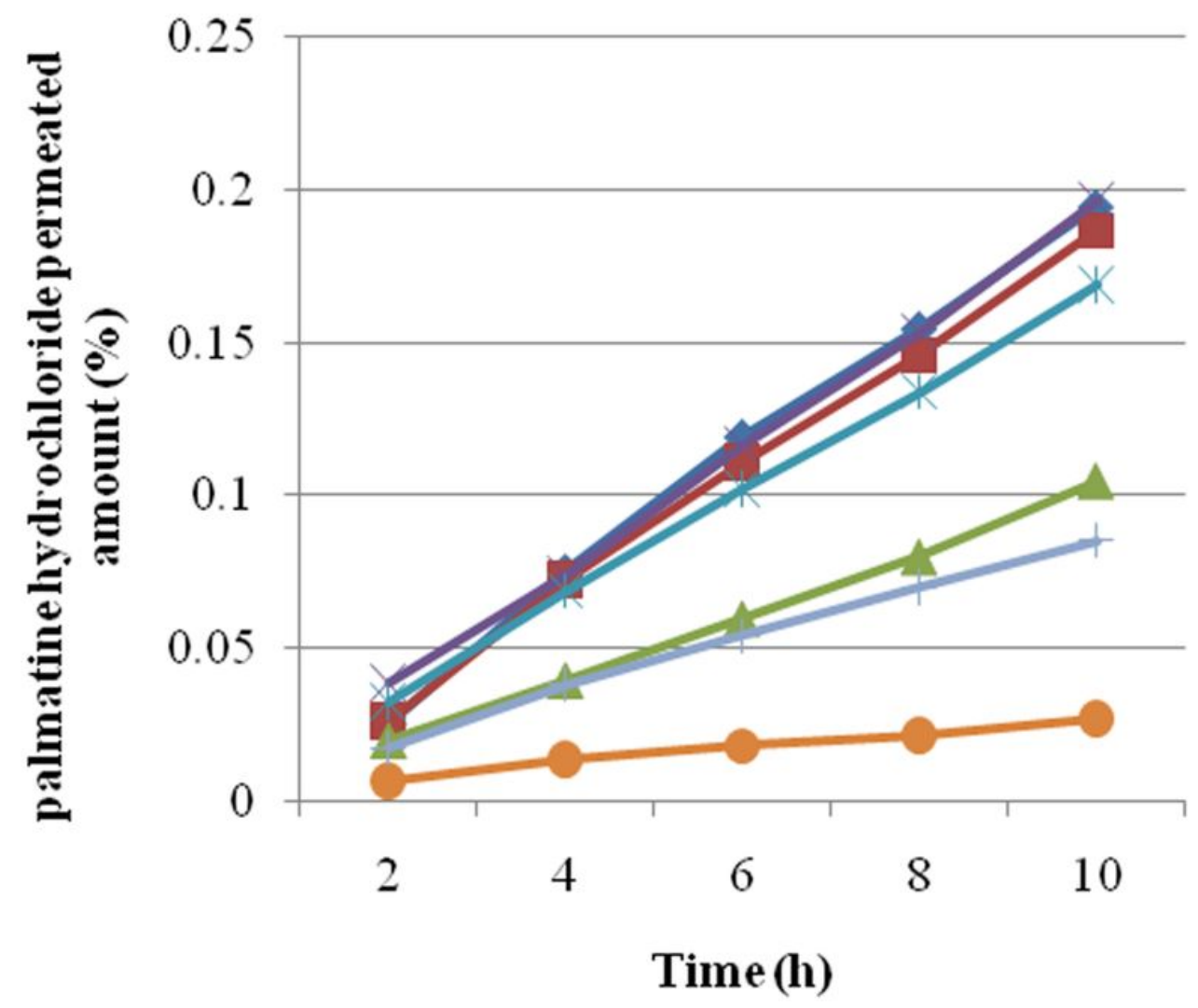

- acetic acid $30 \%$

- acetic acid $35 \%$

- acetic acid $40 \%$

$\longleftarrow$ acetic acid $45 \%$

* acetic acid $50 \%$

- vinegar $100 \%$

$\longrightarrow$ blank control

\section{Figure 3}

Permeation profiles of palmatine hydrochloride in plasters containing $30-50 \% \mathrm{w} / \mathrm{w}$ acetic acid 


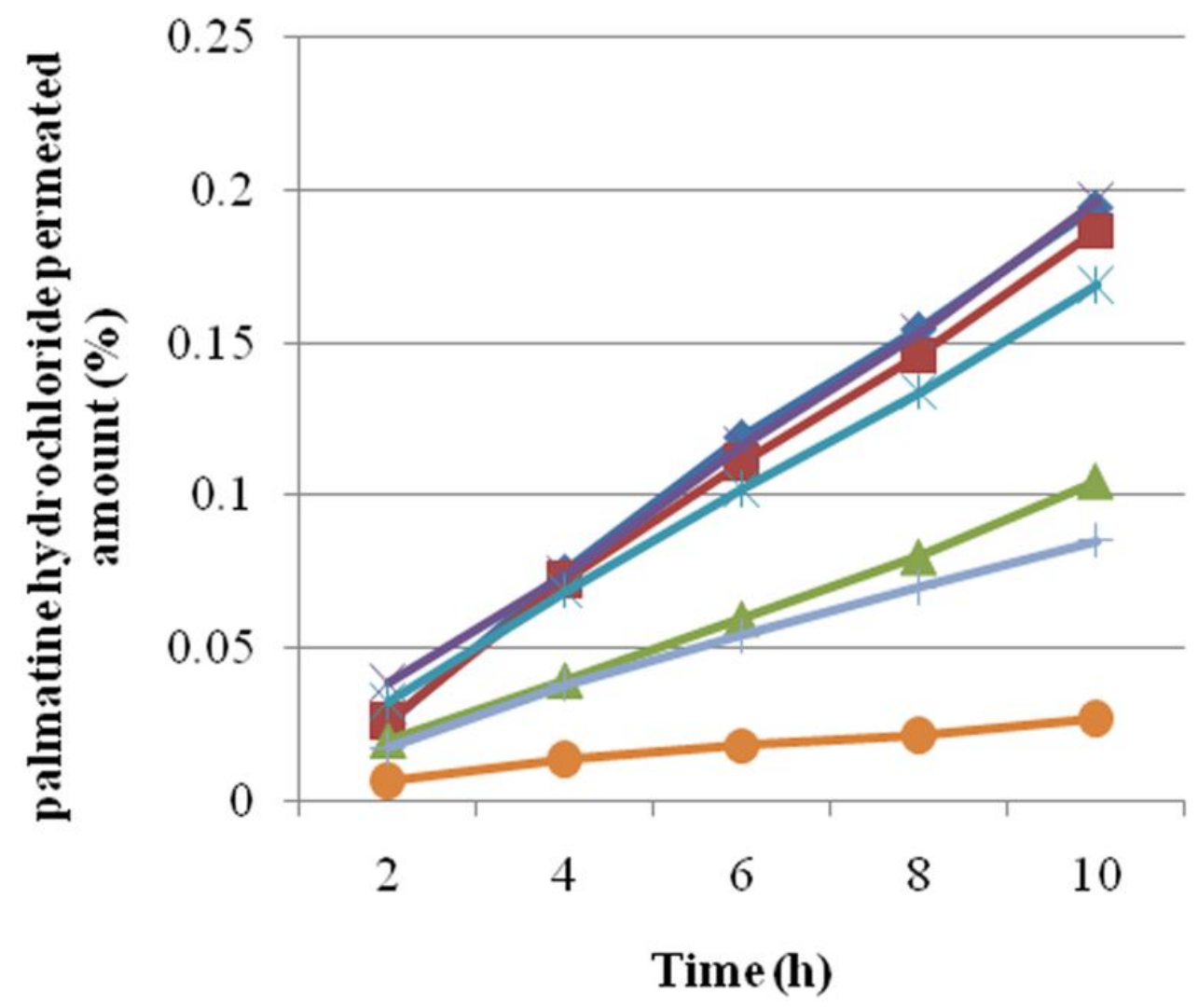

$\longrightarrow$ acetic acid $30 \%$

- acetic acid $35 \%$

- acetic acid $40 \%$

$\longleftarrow$ acetic acid $45 \%$

* acetic acid $50 \%$

- vinegar $100 \%$

$\longrightarrow$ blank control

Time (h)

Figure 3

Permeation profiles of palmatine hydrochloride in plasters containing $30-50 \% \mathrm{w} / \mathrm{w}$ acetic acid 


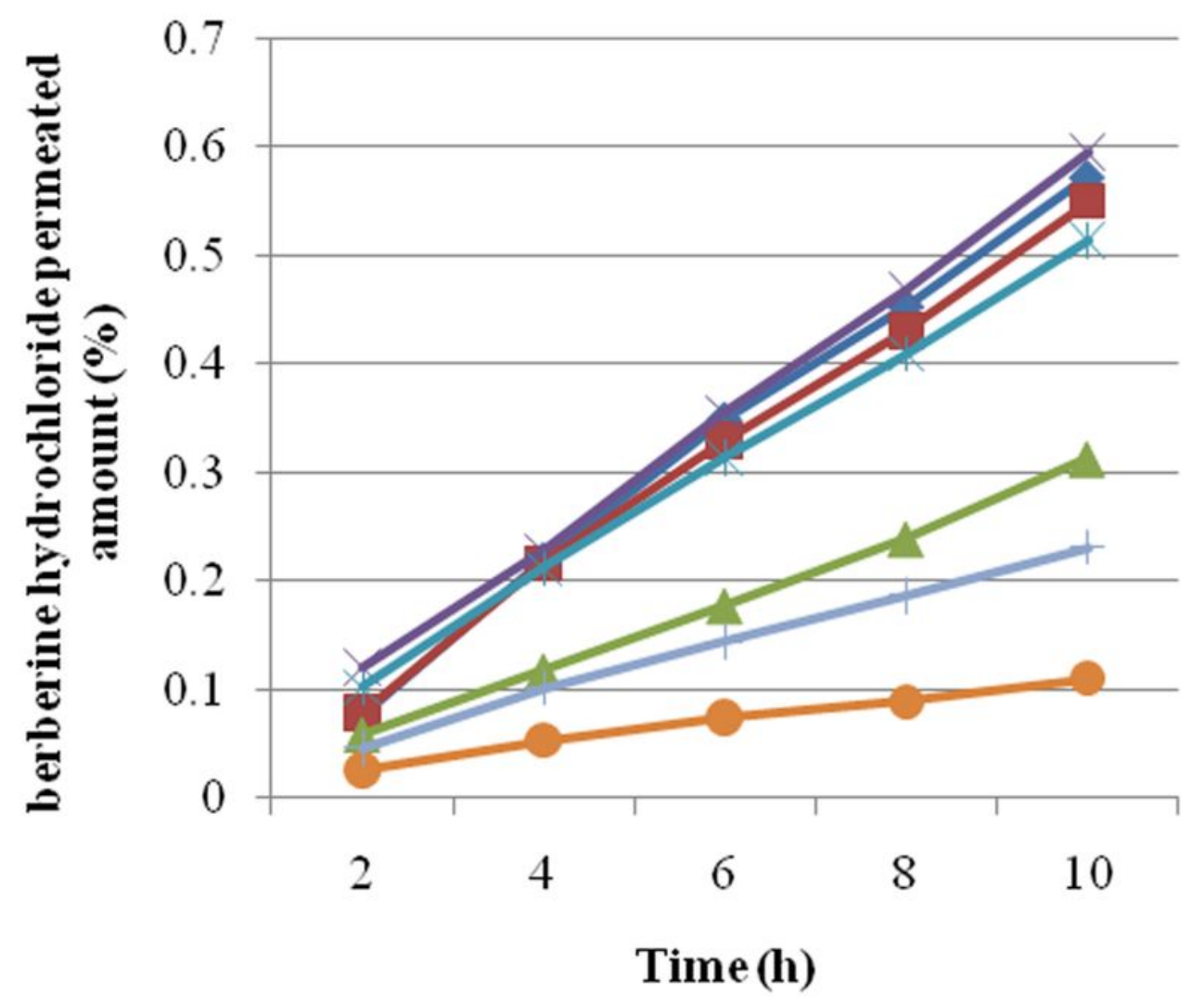

$\longrightarrow$ acetic acid $30 \%$

- - acetic acid $35 \%$

- acetic acid $40 \%$

$\leadsto$ acetic acid $45 \%$

- acetic acid $50 \%$

- - vinegar $100 \%$

$\longrightarrow$ blank control

\section{Figure 4}

Permeation profiles of berberine hydrochloride in plasters containing $30-50 \% \mathrm{w} / \mathrm{w}$ acetic acid 


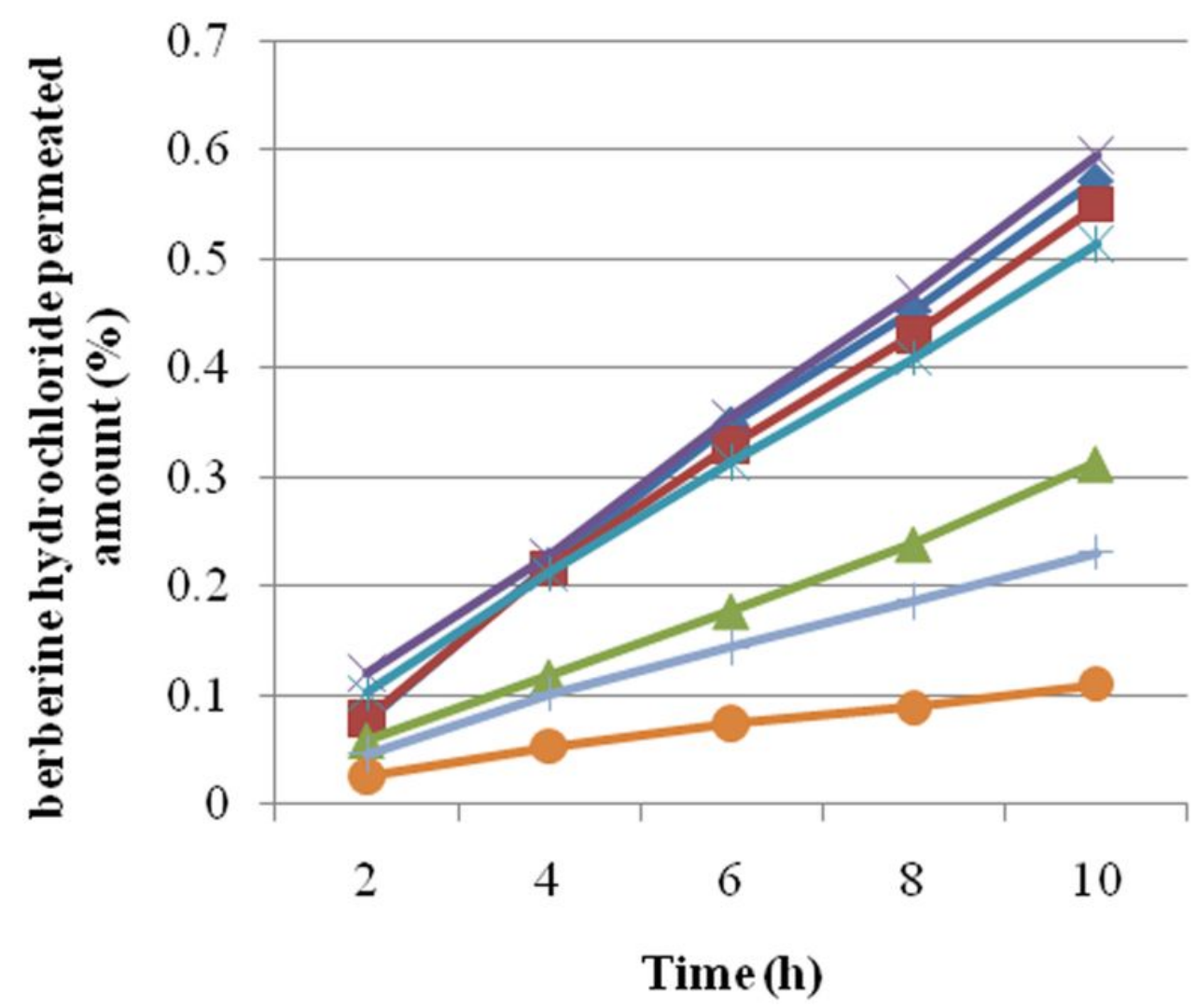

- acetic acid $30 \%$

- acetic acid $35 \%$

- acetic acid $40 \%$

$\leadsto$ acetic acid $45 \%$

*acetic acid $50 \%$

— vinegar $100 \%$

$\longrightarrow$ blank control

\section{Figure 4}

Permeation profiles of berberine hydrochloride in plasters containing $30-50 \% \mathrm{w} / \mathrm{w}$ acetic acid 


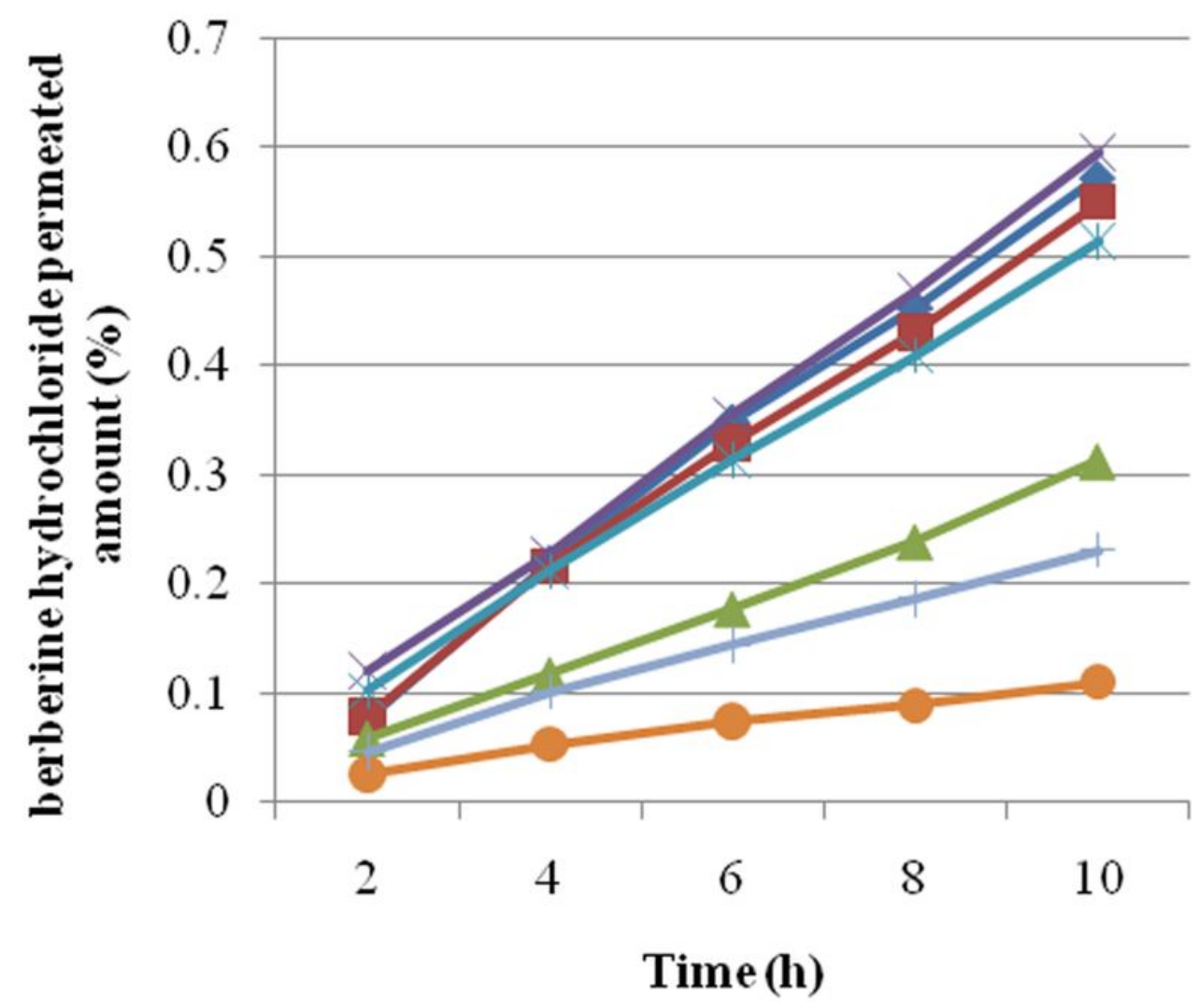

$\longrightarrow$ acetic acid $30 \%$

- - acetic acid $35 \%$

- acetic acid $40 \%$

$\leadsto$ acetic acid $45 \%$

* acetic acid $50 \%$

— - vinegar $100 \%$

$\longrightarrow$ blank control

\section{Figure 4}

Permeation profiles of berberine hydrochloride in plasters containing $30-50 \% \mathrm{w} / \mathrm{w}$ acetic acid 


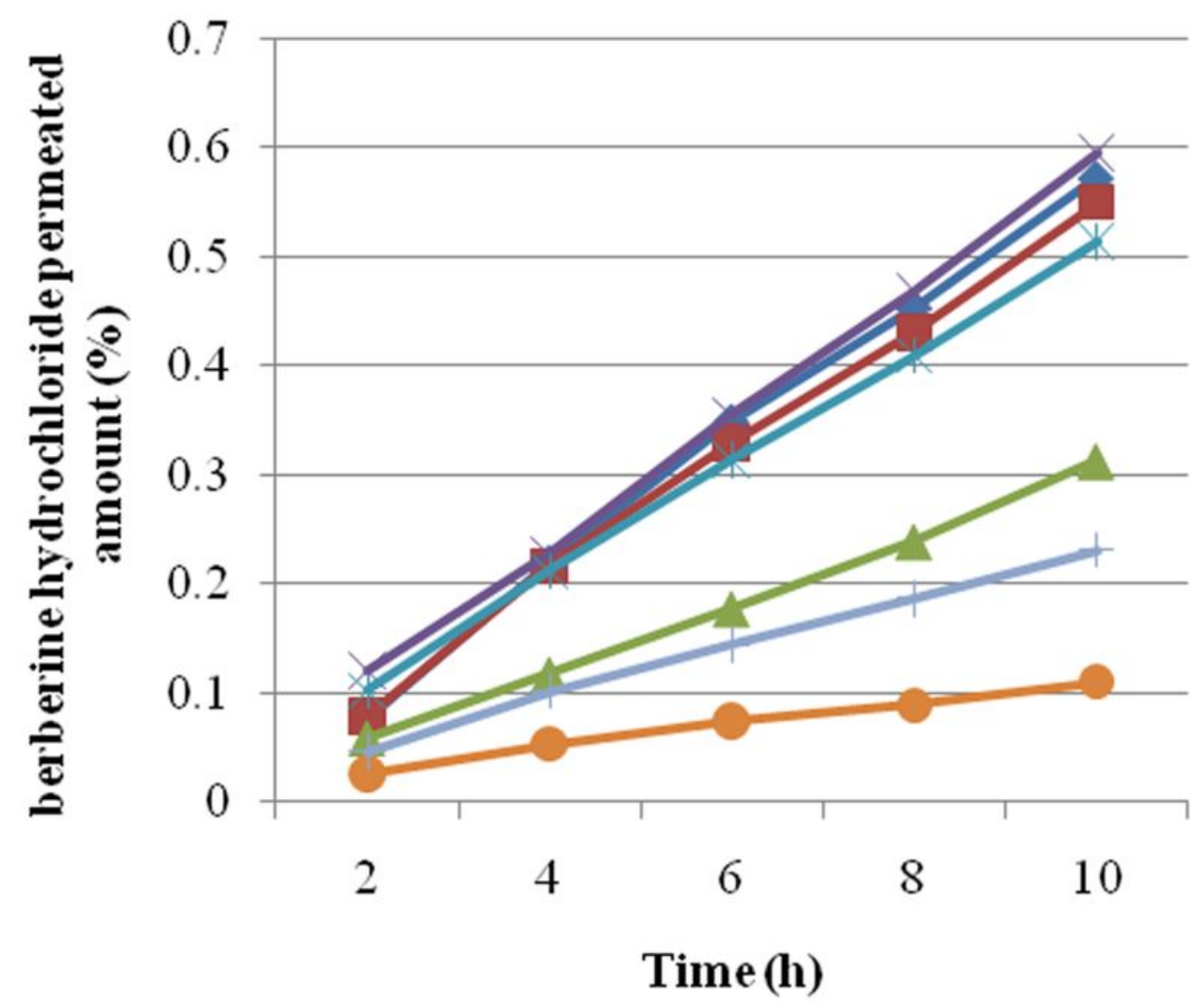

- acetic acid $30 \%$

- - acetic acid $35 \%$

- acetic acid $40 \%$

$\leadsto$ acetic acid $45 \%$

* acetic acid $50 \%$

- - vinegar $100 \%$

$\leftarrow$ blank control

\section{Figure 4}

Permeation profiles of berberine hydrochloride in plasters containing $30-50 \% \mathrm{w} / \mathrm{w}$ acetic acid 


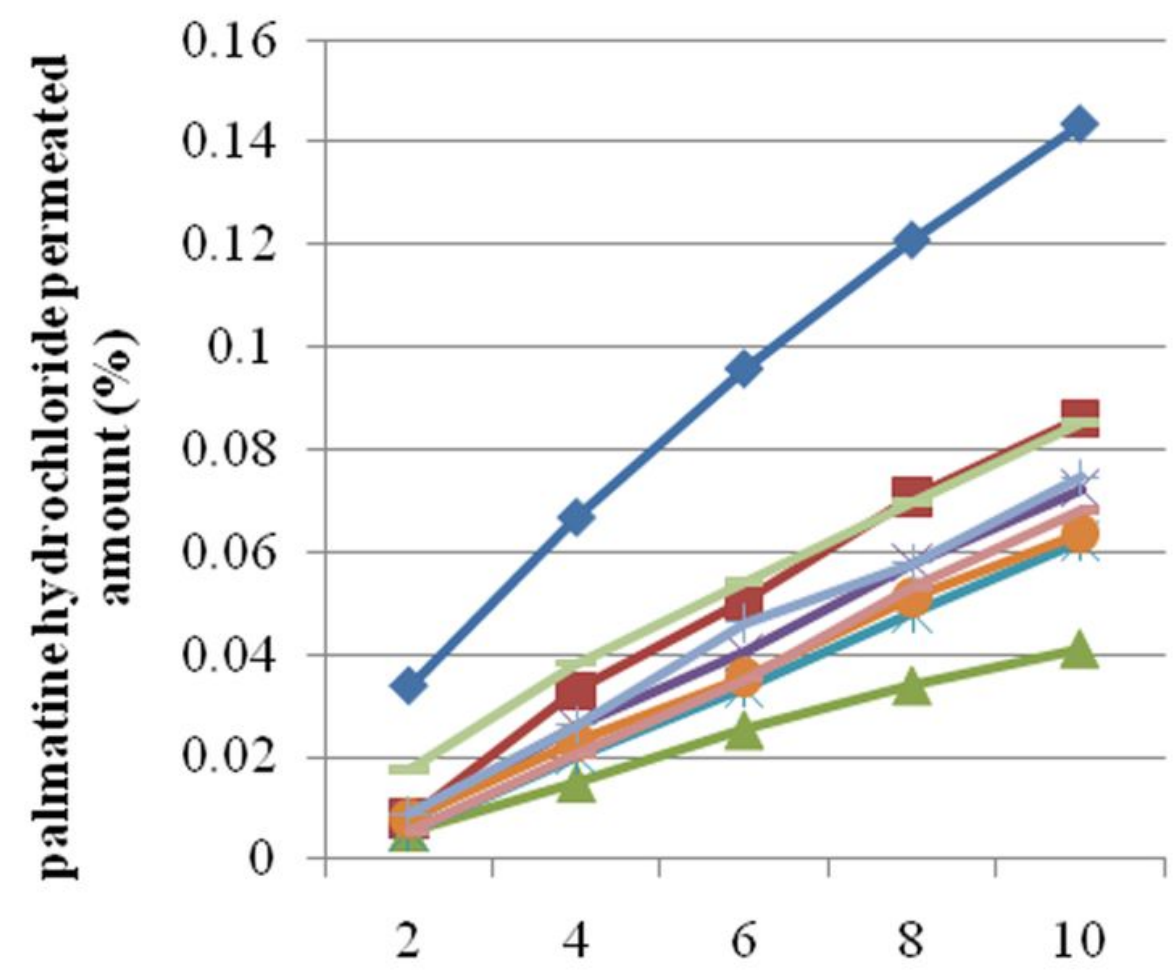

Time (h)

Figure 5

Permeation profiles of palmatine hydrochloride in plasters containing $1-8 \% \mathrm{w} / \mathrm{w}$ water-soluble azone 


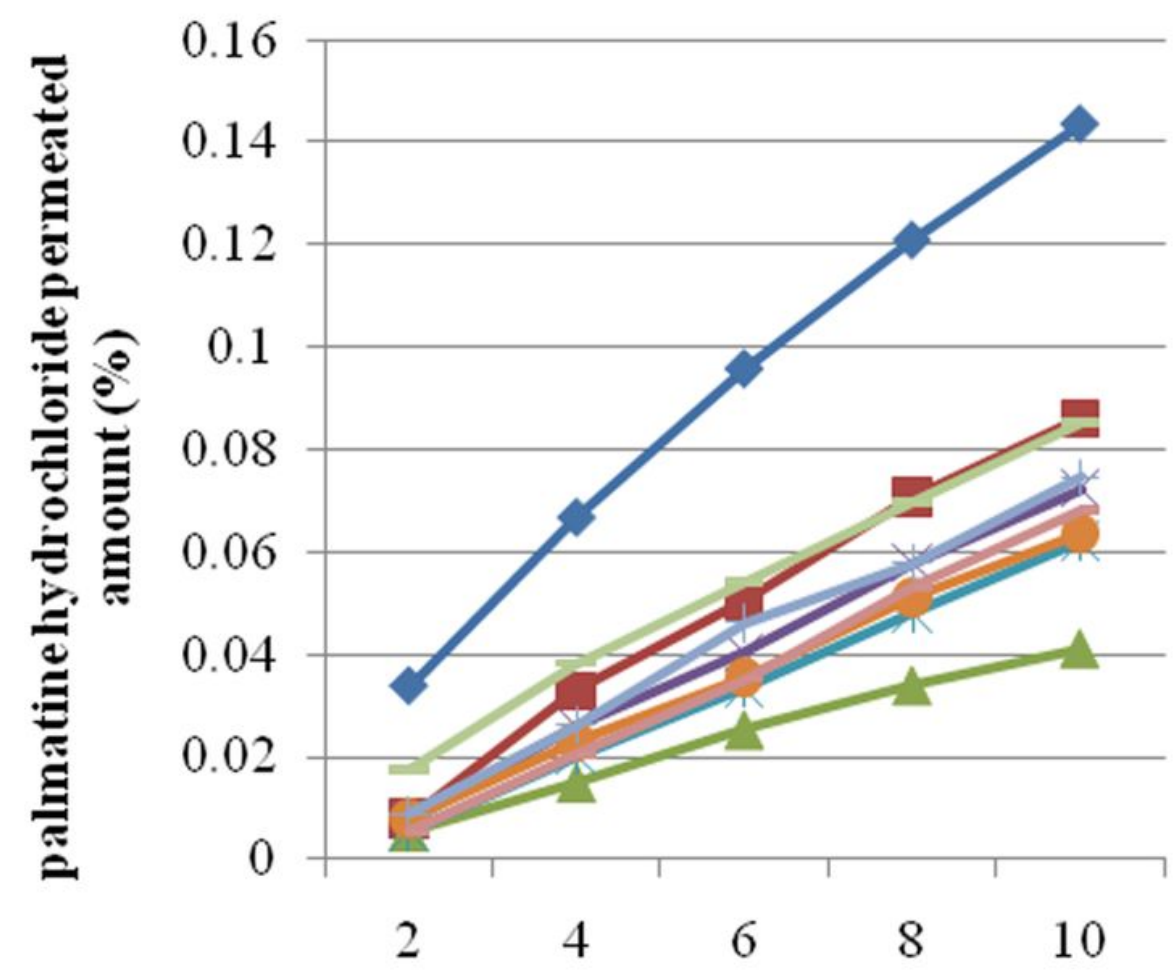

Time (h)

Figure 5

Permeation profiles of palmatine hydrochloride in plasters containing $1-8 \% \mathrm{w} / \mathrm{w}$ water-soluble azone 


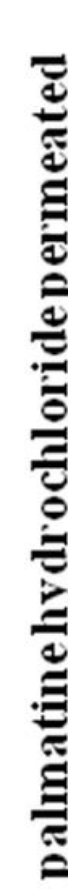

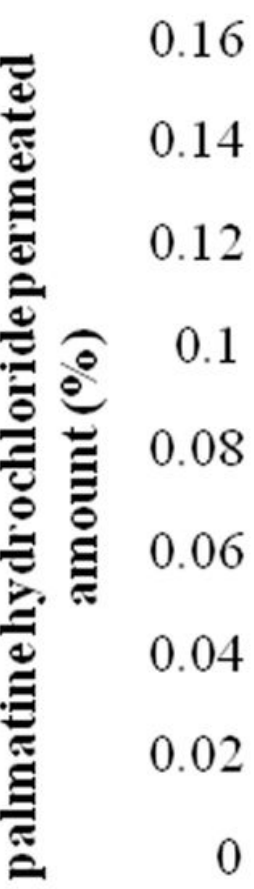
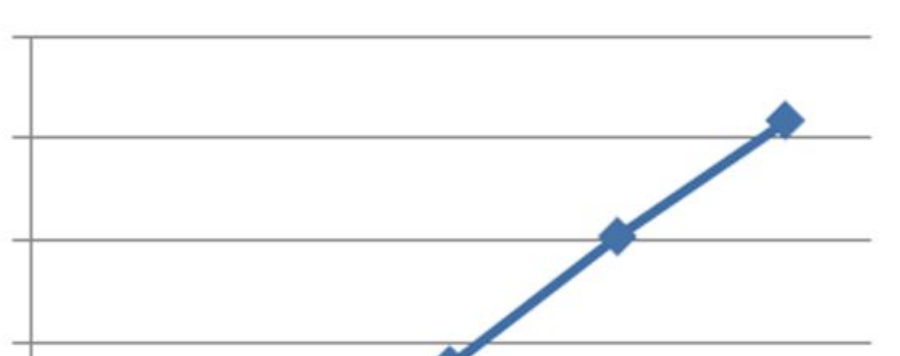

- -water-soluble azone $2 \%$

- water-soluble azone $3 \%$

$\longleftarrow$ water-soluble azone $4 \%$

-water-soluble azone $5 \%$

- water-soluble azone $6 \%$

- water-soluble azone $7 \%$

water-soluble azone $8 \%$

blank control

$\begin{array}{ccc}2 & 4 & 6 \\ & & \text { Time (h) }\end{array}$

Figure 5

Permeation profiles of palmatine hydrochloride in plasters containing $1-8 \% \mathrm{w} / \mathrm{w}$ water-soluble azone 


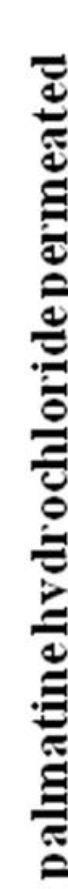

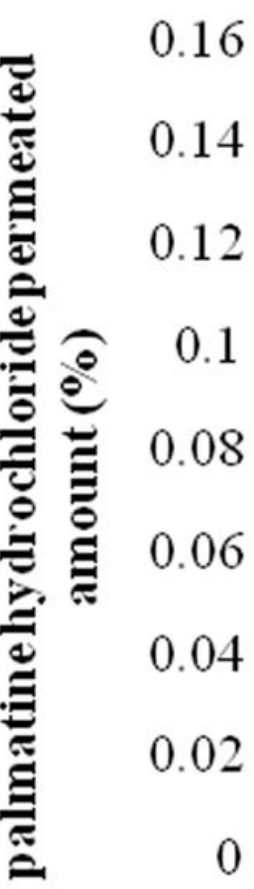
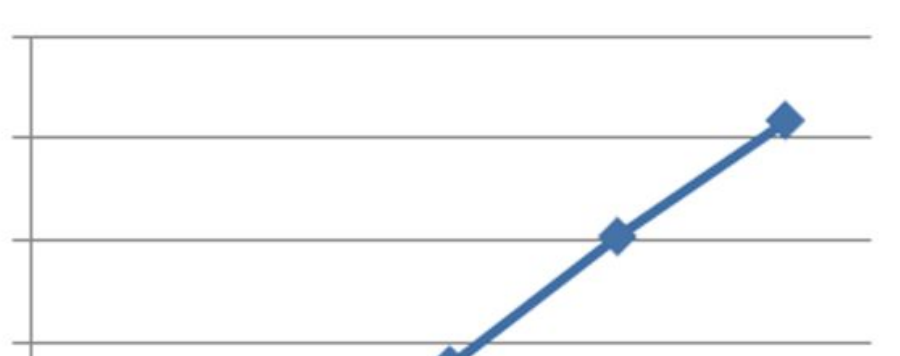

- -water-soluble azone $2 \%$

- water-soluble azone $3 \%$

$\longleftarrow$ water-soluble azone $4 \%$

-water-soluble azone $5 \%$

- water-soluble azone $6 \%$

- water-soluble azone $7 \%$

water-soluble azone $8 \%$

blank control

$\begin{array}{ccc}2 & 4 & 6 \\ & & \text { Time (h) }\end{array}$

Figure 5

Permeation profiles of palmatine hydrochloride in plasters containing $1-8 \% \mathrm{w} / \mathrm{w}$ water-soluble azone 


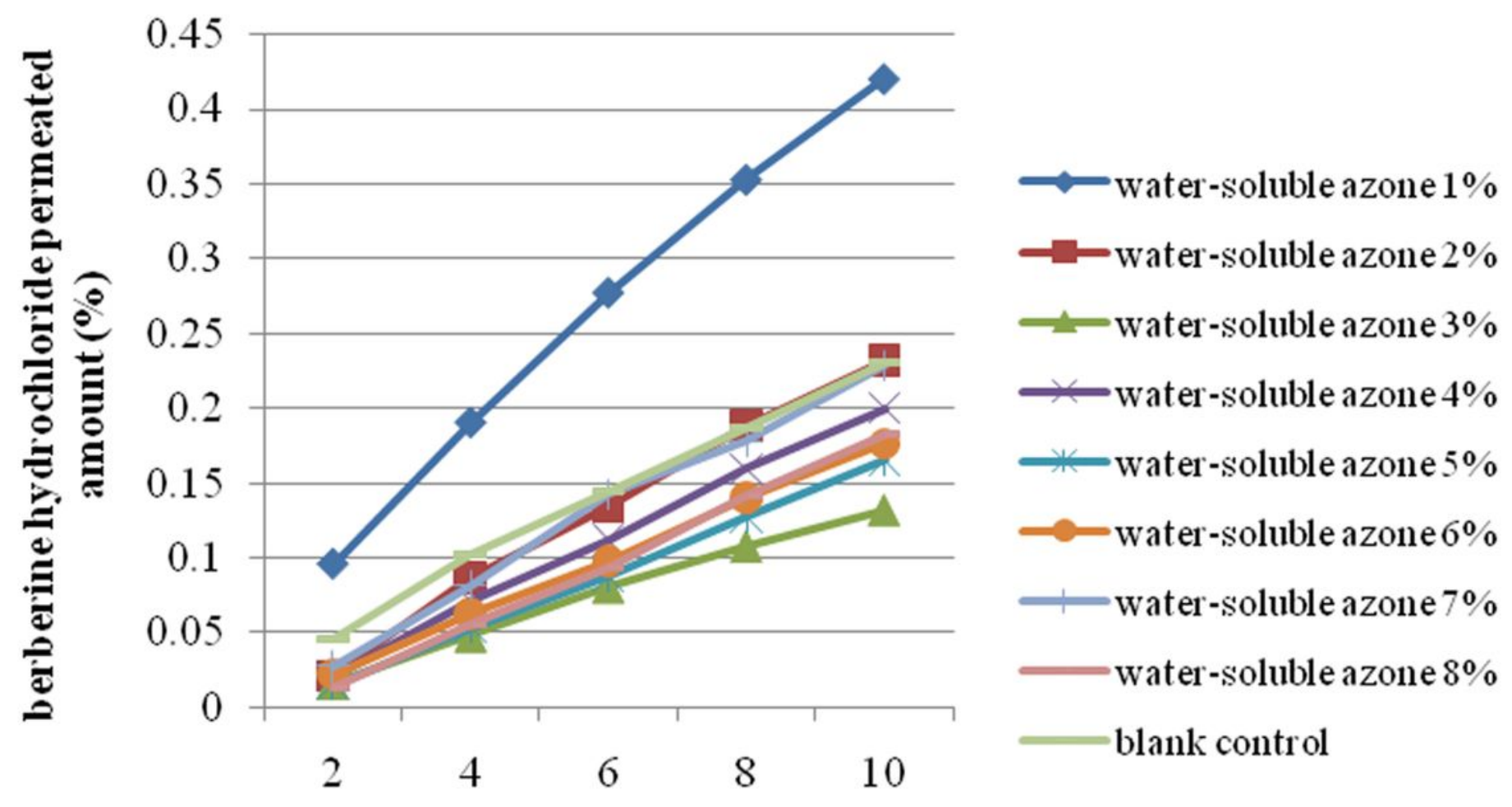

Time (h)

Figure 6

Permeation profiles of berberine hydrochloride in plasters containing $1-8 \% \mathrm{w} / \mathrm{w}$ water-soluble azone 


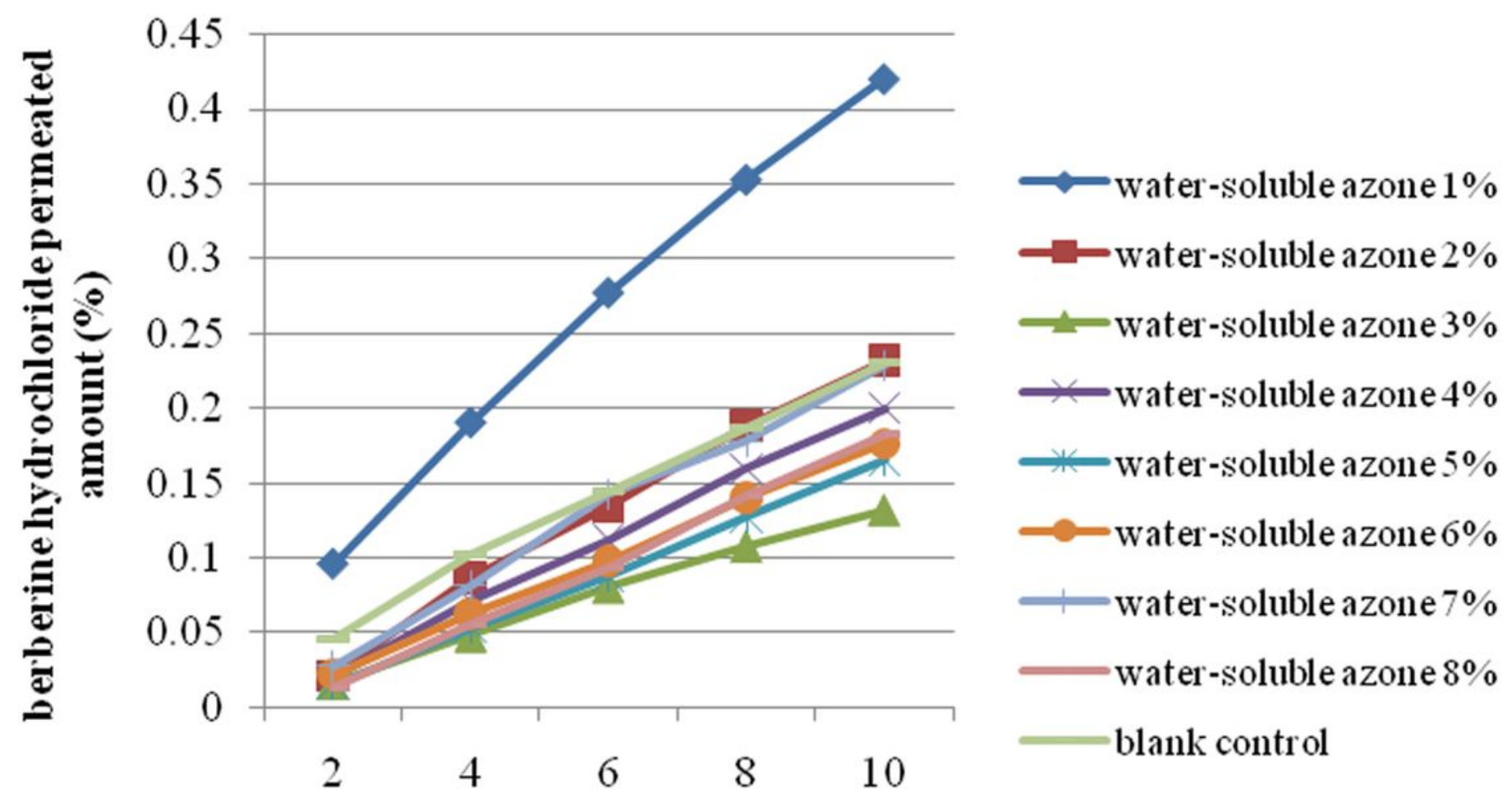

Time (h)

Figure 6

Permeation profiles of berberine hydrochloride in plasters containing $1-8 \% \mathrm{w} / \mathrm{w}$ water-soluble azone 


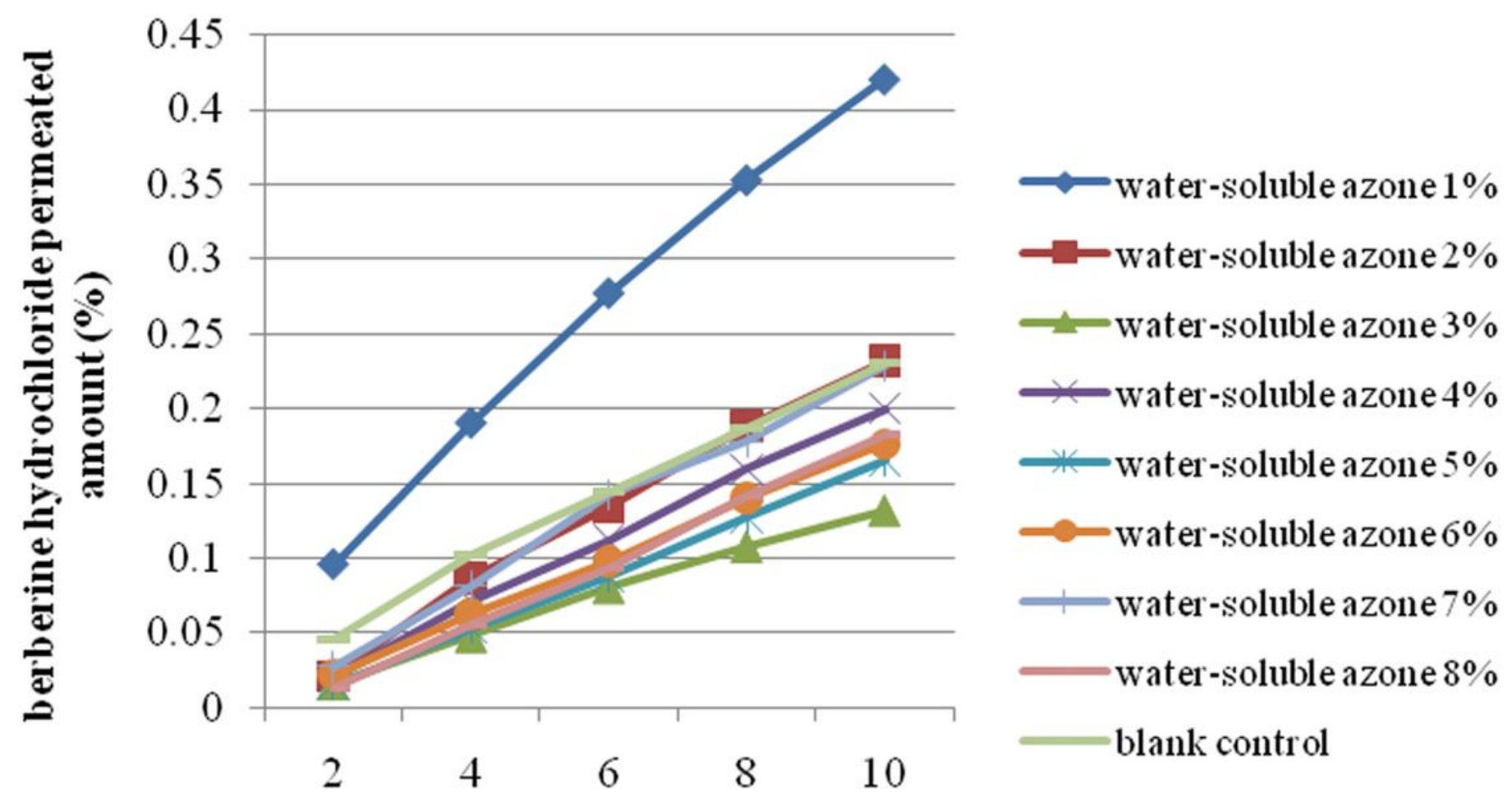

Time (h)

Figure 6

Permeation profiles of berberine hydrochloride in plasters containing $1-8 \% \mathrm{w} / \mathrm{w}$ water-soluble azone 


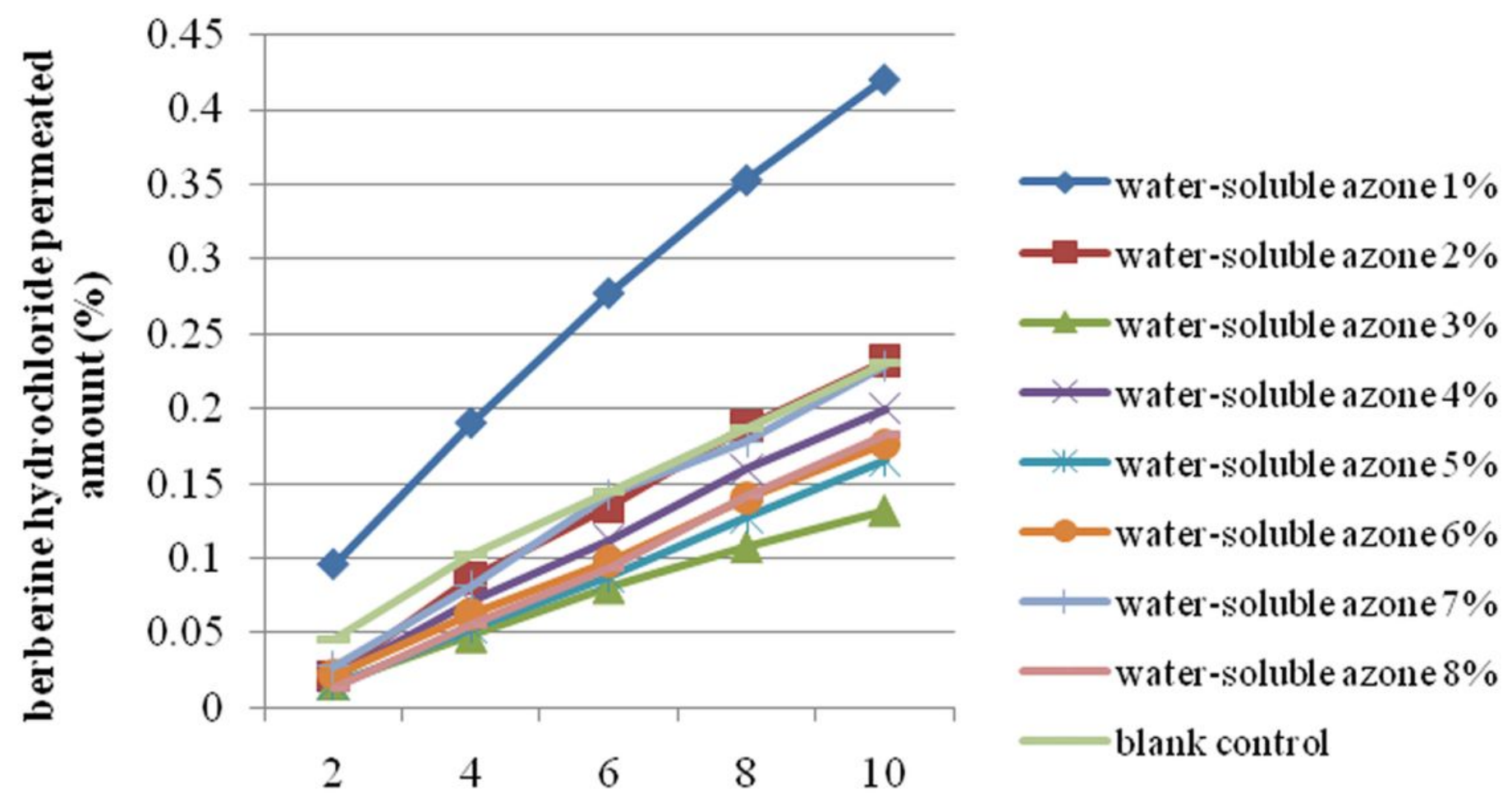

Time (h)

Figure 6

Permeation profiles of berberine hydrochloride in plasters containing $1-8 \% \mathrm{w} / \mathrm{w}$ water-soluble azone 


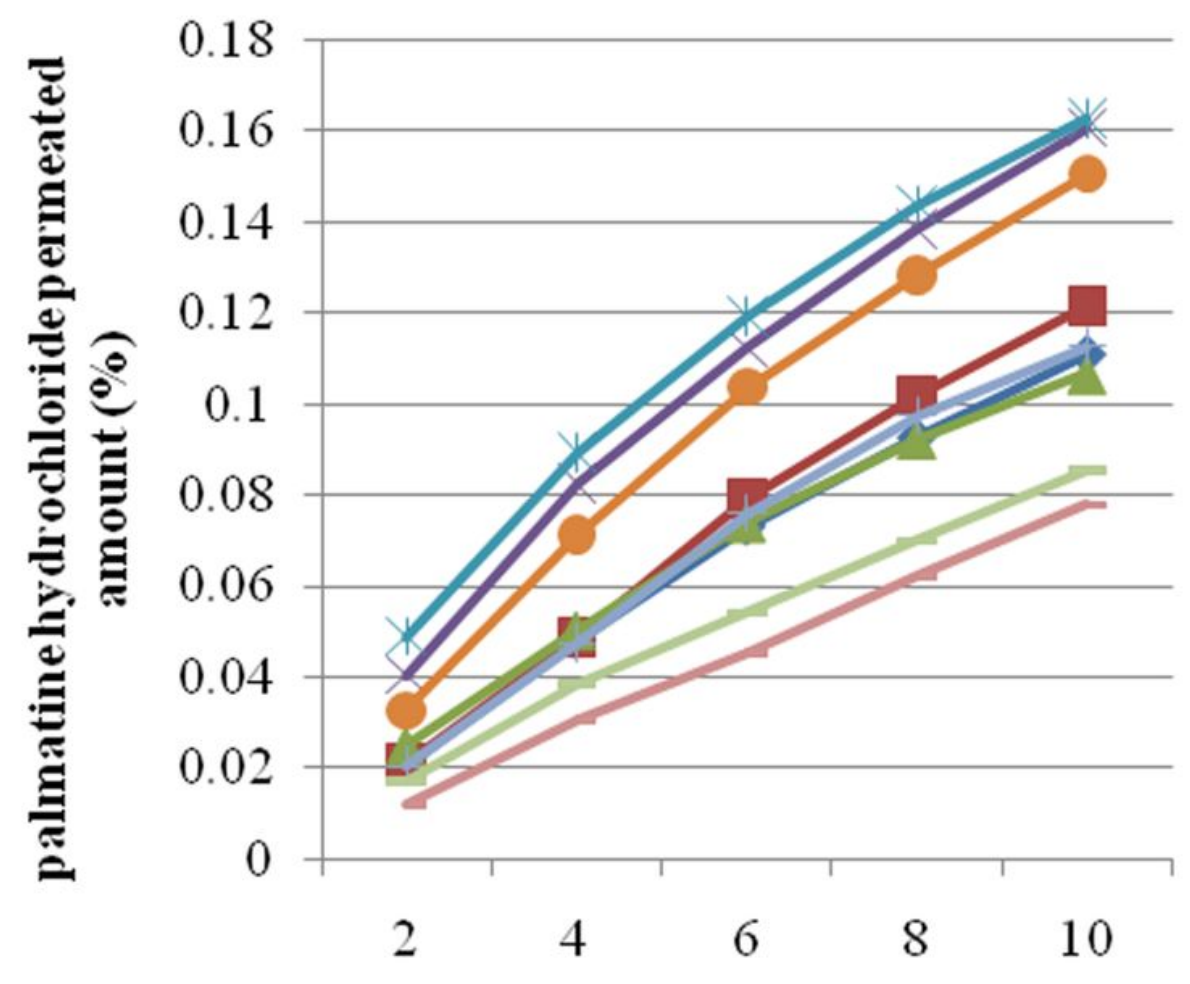

—fat-soluble azone $1 \%$

- fat-soluble azone $2 \%$

-f fat-soluble azone $3 \%$

$\sim$ fat-soluble azone $4 \%$

-fat-soluble azone 5\%

- fat-soluble azone $6 \%$

_ fat-soluble azone 7\%

fat-soluble azone $8 \%$

blank control

\section{Time (h)}

Figure 7

Permeation profiles of palmatine hydrochloride in plasters containing $1-8 \% \mathrm{w} / \mathrm{w}$ fat-soluble azone 


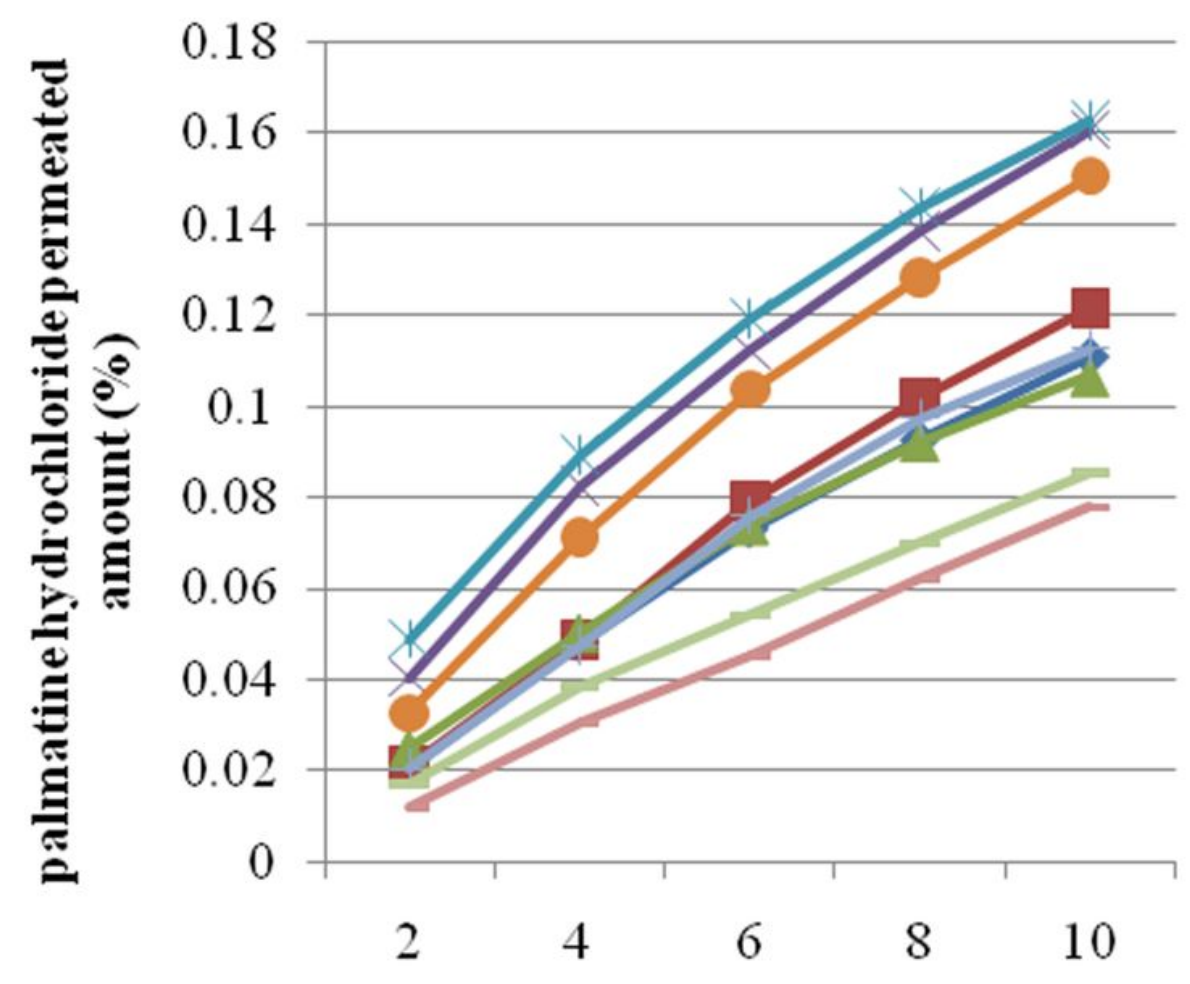

$\smile$ fat-soluble azone $1 \%$

- fat-soluble azone $2 \%$

- fat-soluble azone $3 \%$

$\simeq$ fat-soluble azone $4 \%$

fat-soluble azone $5 \%$

- fat-soluble azone $6 \%$

_ fat-soluble azone $7 \%$

fat-soluble azone $8 \%$

blank control

\section{Time (h)}

Figure 7

Permeation profiles of palmatine hydrochloride in plasters containing $1-8 \% \mathrm{w} / \mathrm{w}$ fat-soluble azone 


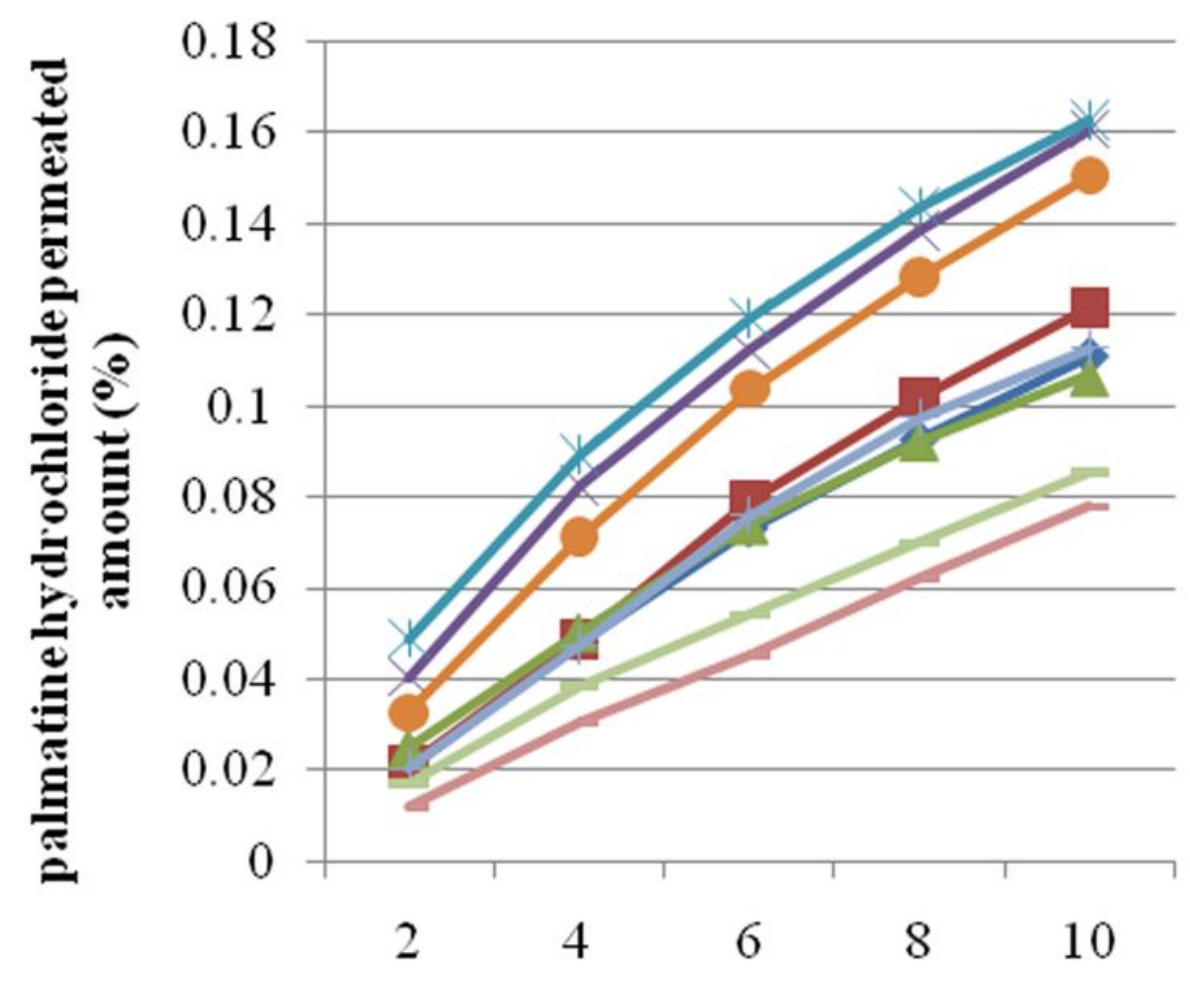

—fat-soluble azone $1 \%$

- fat-soluble azone $2 \%$

- fat-soluble azone $3 \%$

$\varkappa$ fat-soluble azone $4 \%$

类 fat-soluble azone 5\%

- fat-soluble azone $6 \%$

_ fat-soluble azone $7 \%$

fat-soluble azone $8 \%$

blank control

\section{Time (h)}

Figure 7

Permeation profiles of palmatine hydrochloride in plasters containing $1-8 \% \mathrm{w} / \mathrm{w}$ fat-soluble azone 


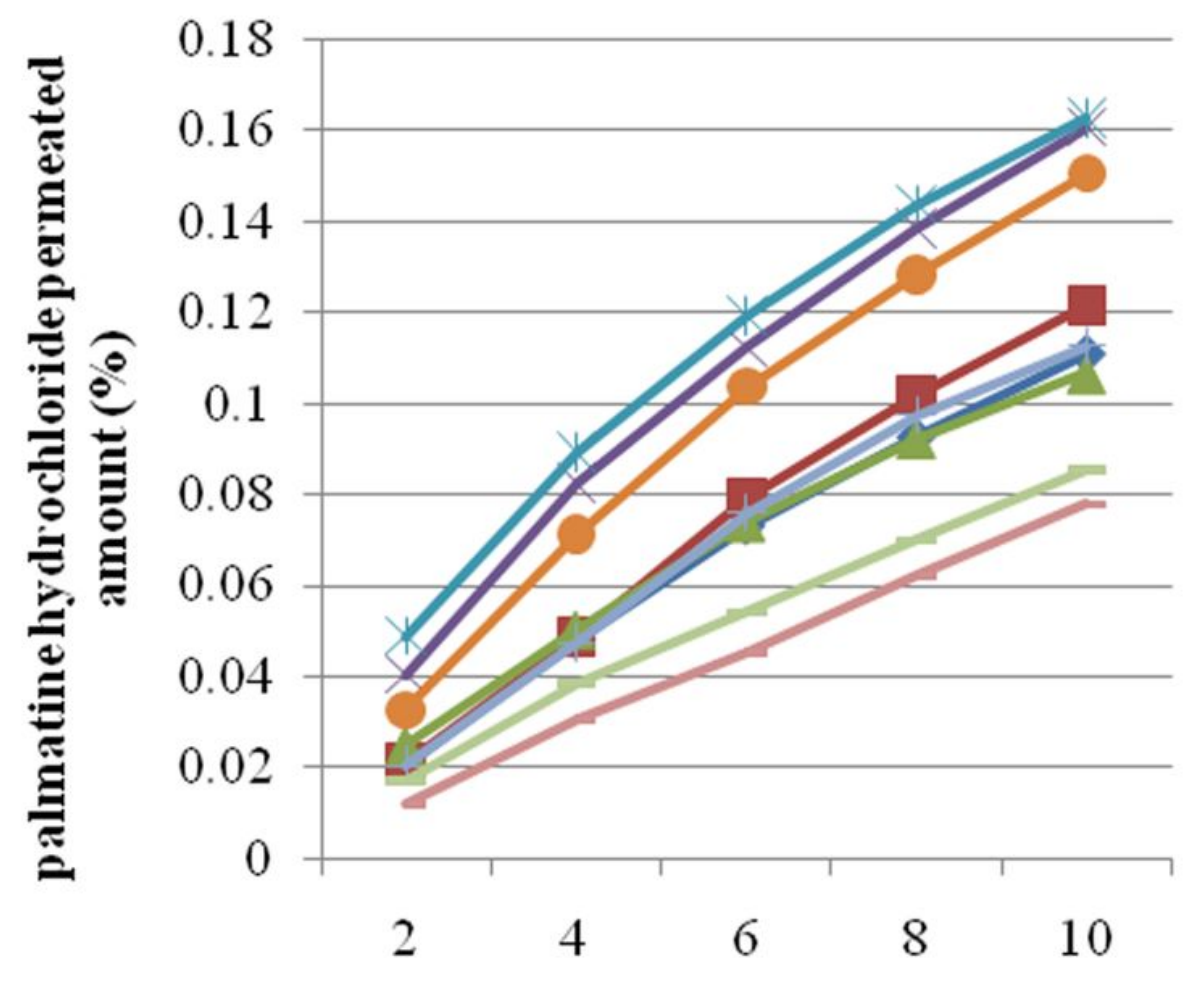

$\smile$ fat-soluble azone $1 \%$

- fat-soluble azone $2 \%$

- fat-soluble azone $3 \%$

$\varkappa$ fat-soluble azone $4 \%$

类 fat-soluble azone $5 \%$

- fat-soluble azone $6 \%$

- fat-soluble azone $7 \%$

fat-soluble azone $8 \%$

blank control

\section{Time (h)}

Figure 7

Permeation profiles of palmatine hydrochloride in plasters containing $1-8 \% \mathrm{w} / \mathrm{w}$ fat-soluble azone 


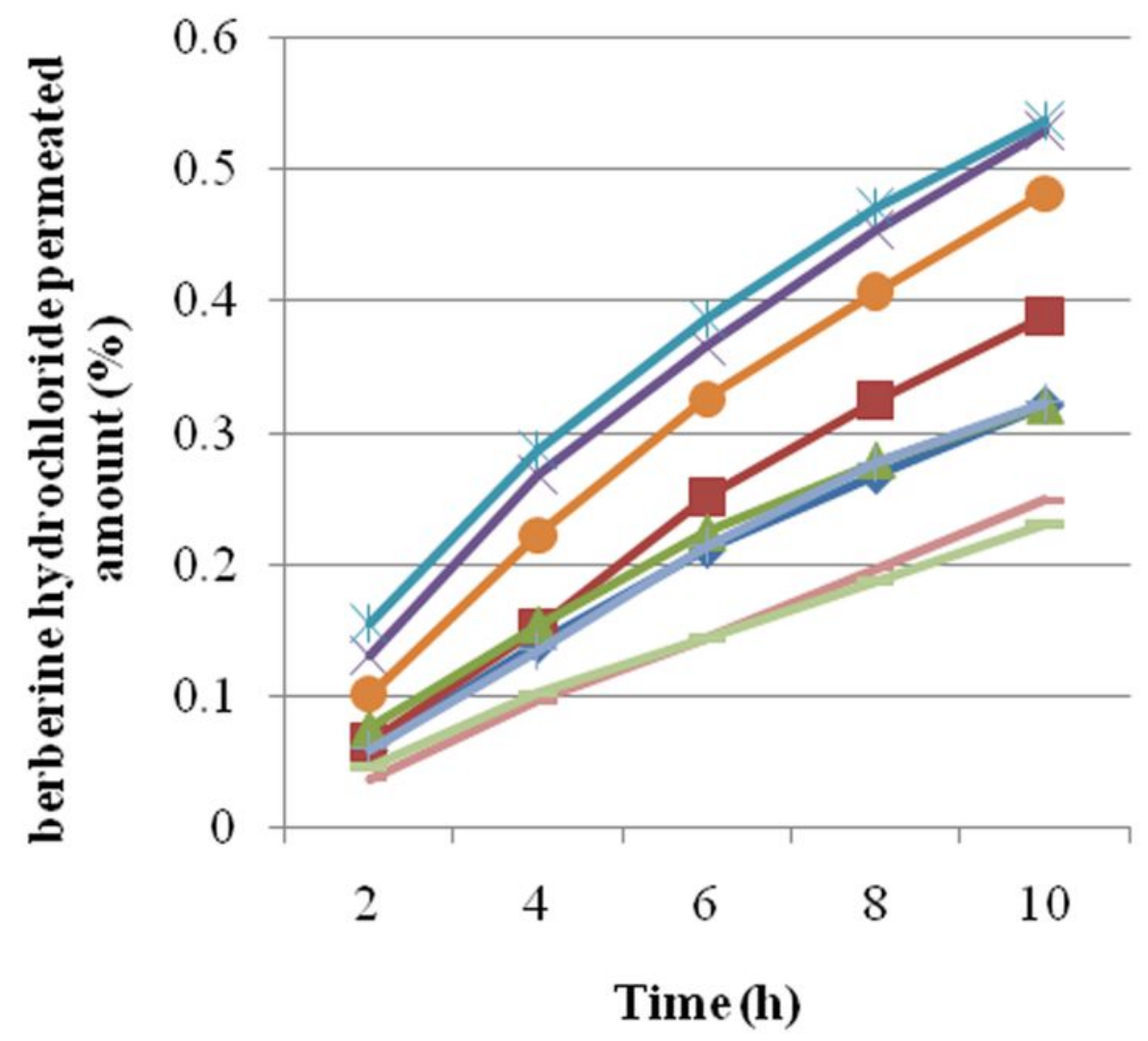

-fat-soluble azone $1 \%$

- fat-soluble azone $2 \%$

- fat-soluble azone $3 \%$

$\leadsto$ fat-soluble azone $4 \%$

* fat-soluble azone $5 \%$

- fat-soluble azone $6 \%$

_ fat-soluble azone $7 \%$

fat-soluble azone $8 \%$ blank control

\section{Figure 8}

Permeation profiles of berberine hydrochloride in plasters containing $1-8 \% \mathrm{w} / \mathrm{w}$ fat-soluble azone 


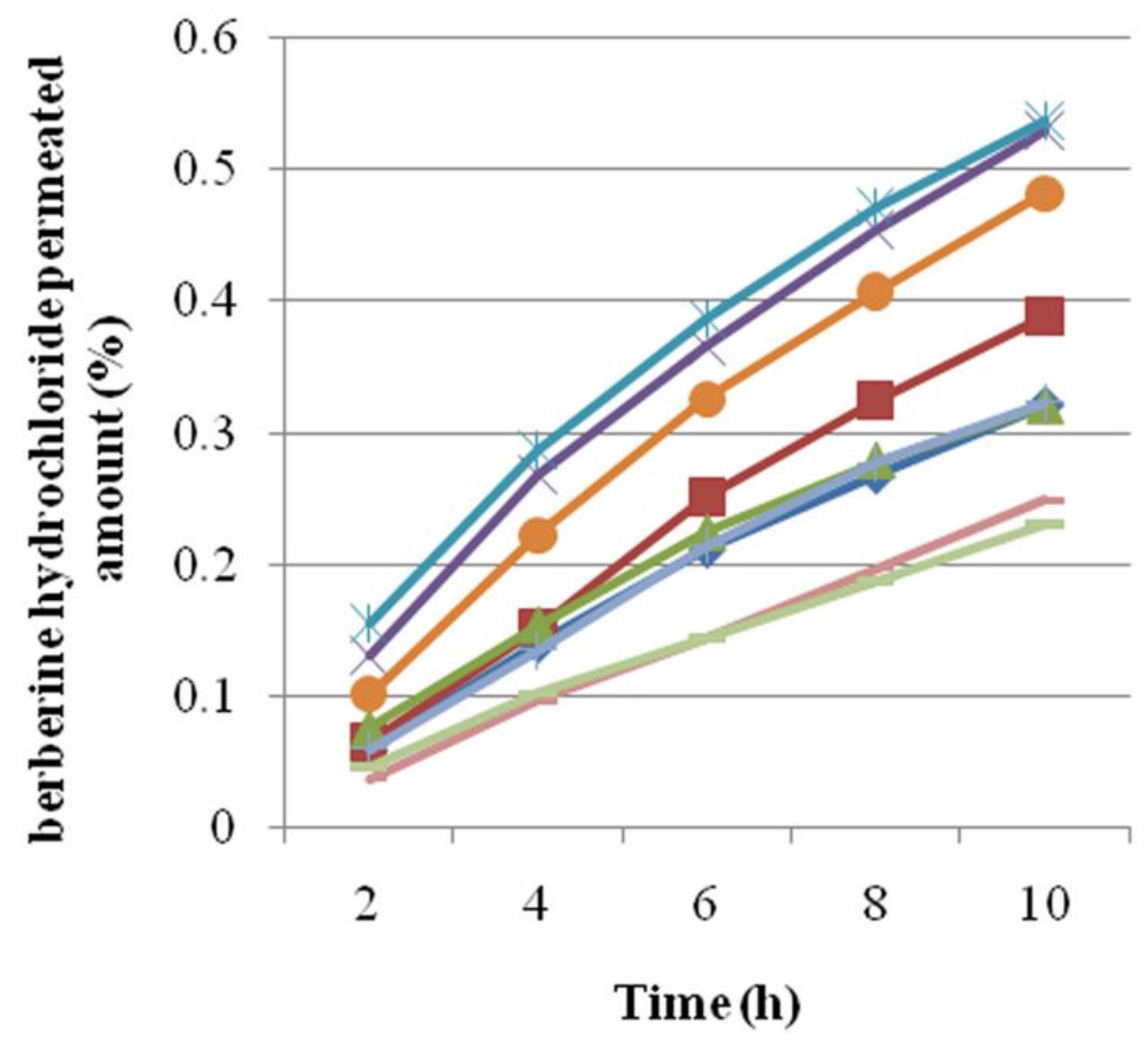

-fat-soluble azone $1 \%$

- fat-soluble azone $2 \%$

- fat-soluble azone $3 \%$

$\leadsto$ fat-soluble azone $4 \%$

* fat-soluble azone $5 \%$

- fat-soluble azone $6 \%$

_ fat-soluble azone $7 \%$

- fat-soluble azone $8 \%$ blank control

\section{Figure 8}

Permeation profiles of berberine hydrochloride in plasters containing $1-8 \% \mathrm{w} / \mathrm{w}$ fat-soluble azone 


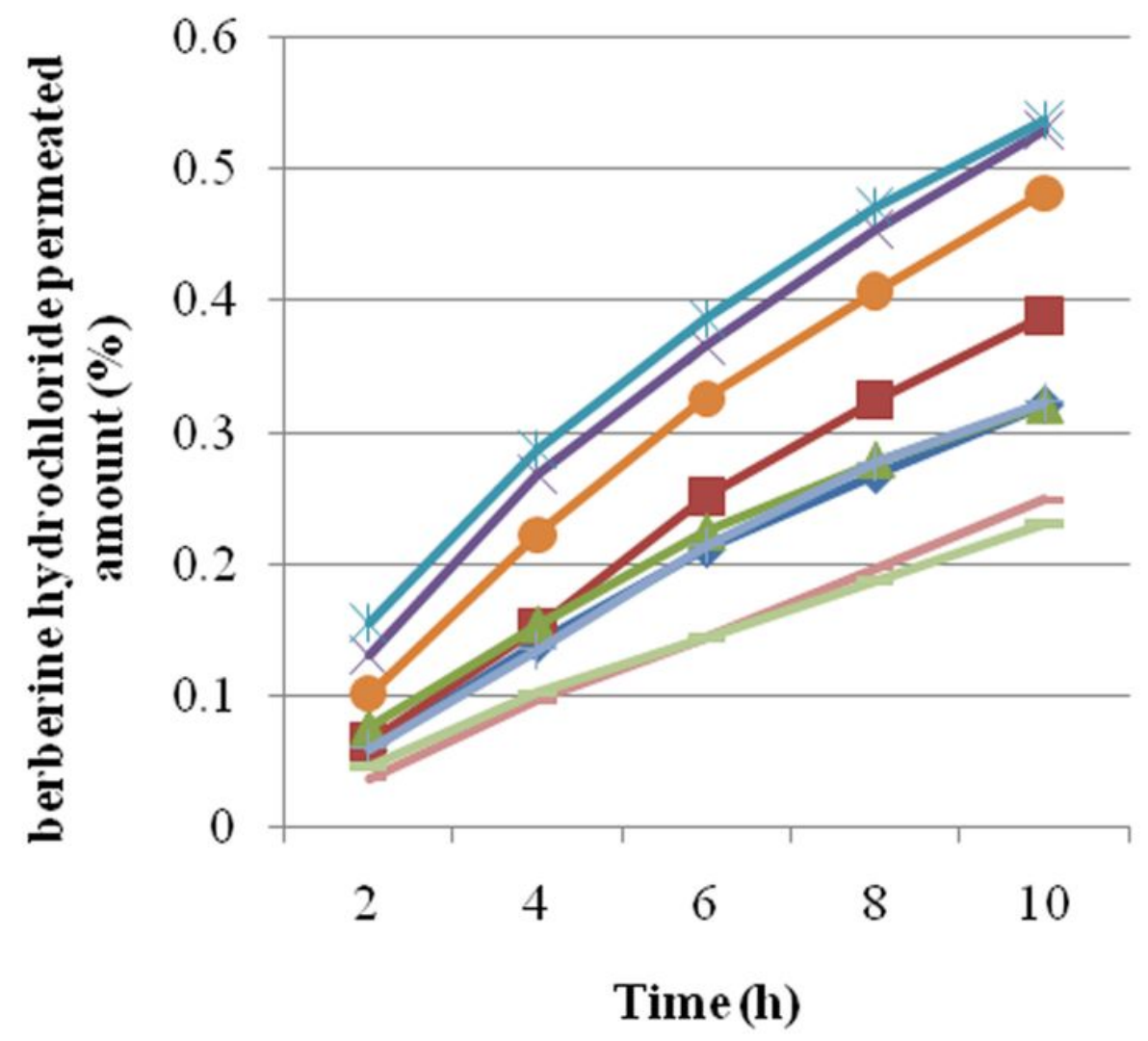

—fat-soluble azone $1 \%$

- fat-soluble azone $2 \%$

-f fat-soluble azone $3 \%$

$\leadsto$ fat-soluble azone $4 \%$

* fat-soluble azone $5 \%$

- fat-soluble azone $6 \%$

_ fat-soluble azone $7 \%$

—fat-soluble azone $8 \%$ blank control

\section{Time (h)}

Figure 8

Permeation profiles of berberine hydrochloride in plasters containing $1-8 \% \mathrm{w} / \mathrm{w}$ fat-soluble azone 


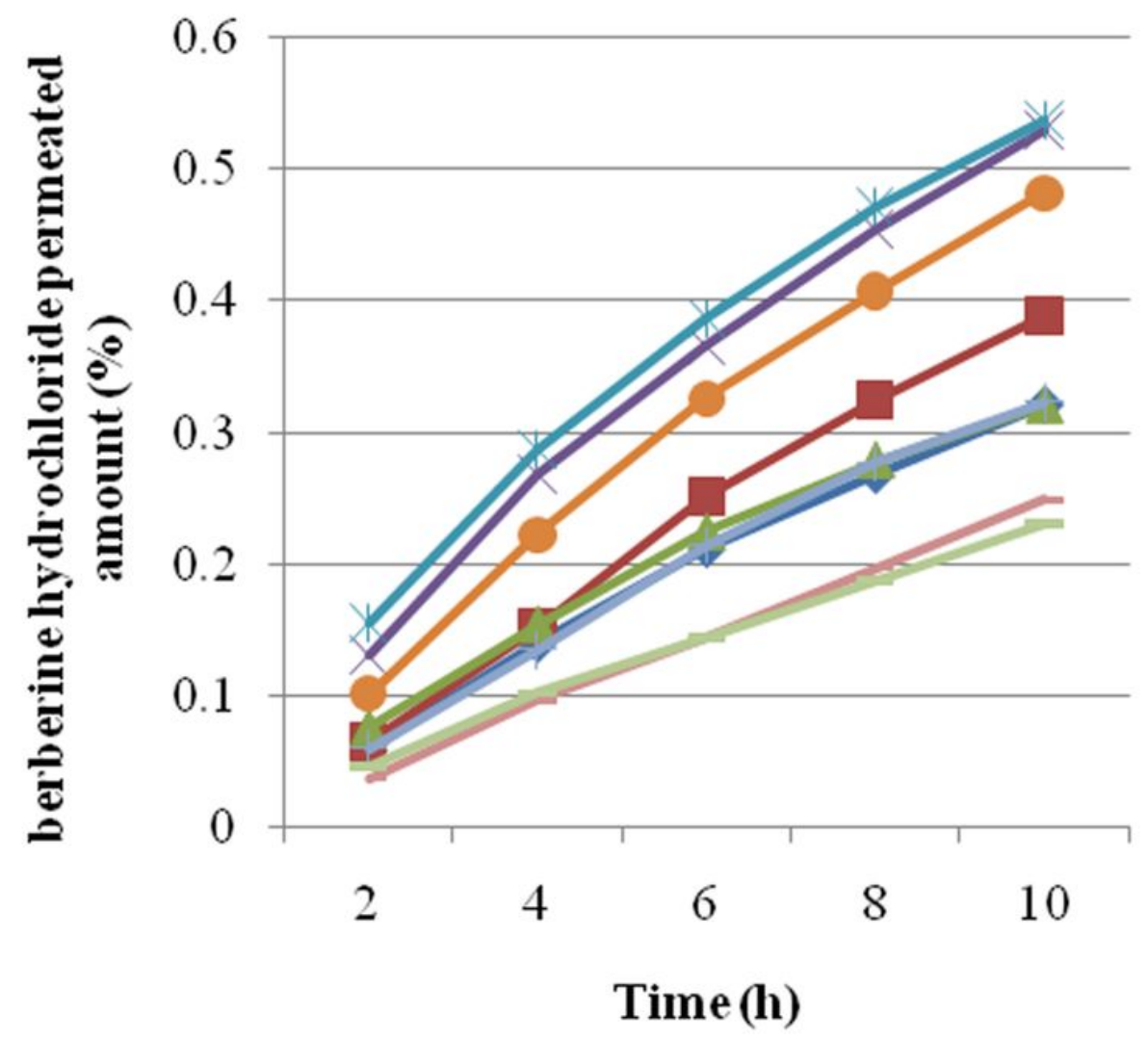

—fat-soluble azone $1 \%$

- fat-soluble azone $2 \%$

-f fat-soluble azone $3 \%$

$\leadsto$ fat-soluble azone $4 \%$

* fat-soluble azone $5 \%$

- fat-soluble azone $6 \%$

_ fat-soluble azone $7 \%$

—fat-soluble azone $8 \%$ blank control

\section{Time (h)}

Figure 8

Permeation profiles of berberine hydrochloride in plasters containing $1-8 \% \mathrm{w} / \mathrm{w}$ fat-soluble azone 

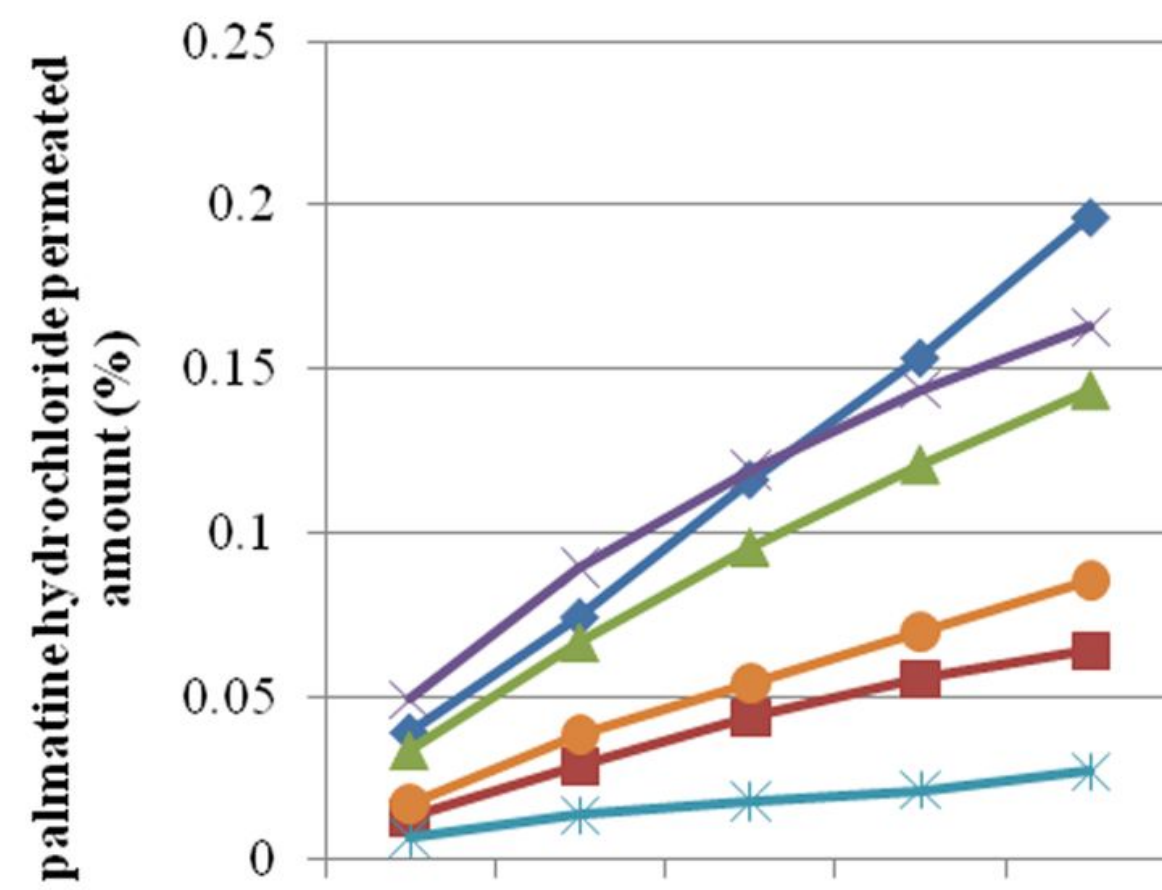

$-50 \%$ dimethyl sulfoxide

$-1 \%$ water-soluble azone

$\leftarrow 5 \%$ fat-soluble azone

(1)

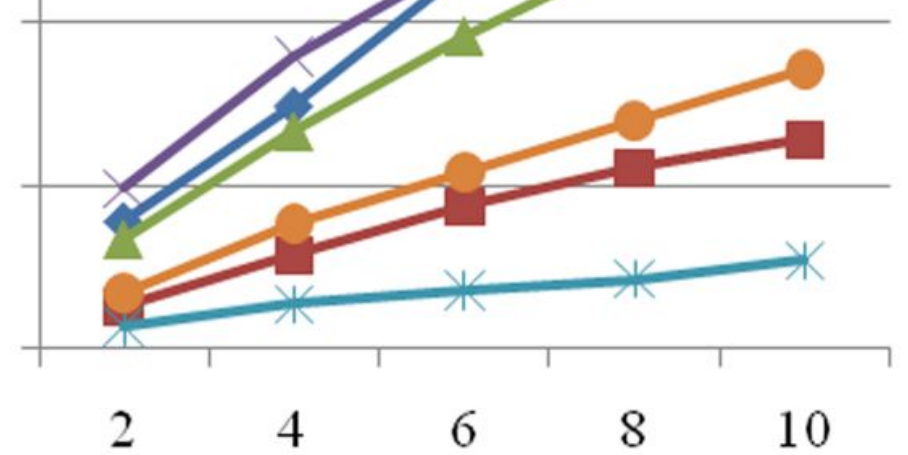

米 $100 \%$ vinegar

- blank control

Time (h)

Figure 9

Permeation profiles of palmatine hydrochloride in plasters containing transdermal promoter with best skin penetration effects in their respective series 


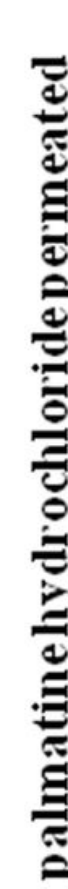

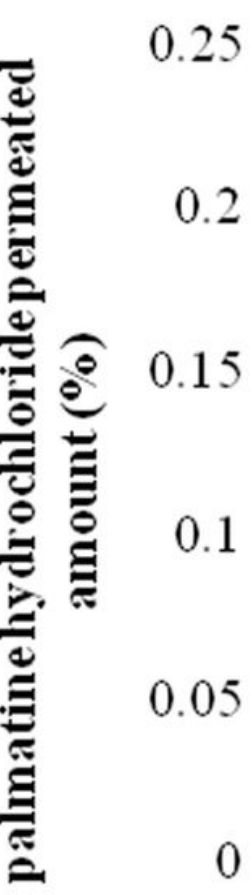
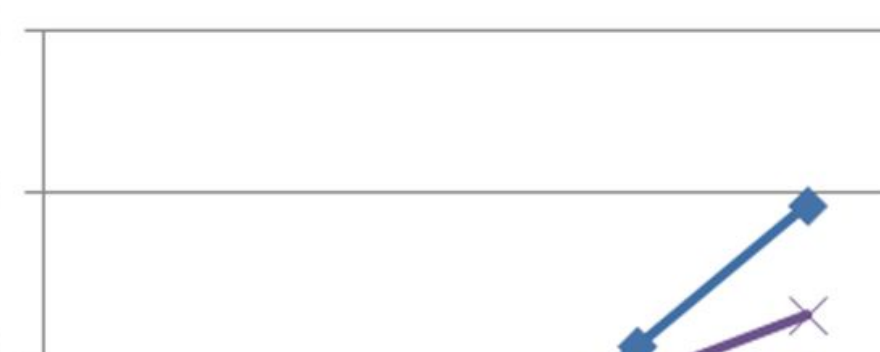

$-50 \%$ dimethyl sulfoxide

$-1 \%$ water-soluble azone

$\leftarrow 5 \%$ fat-soluble azone

西

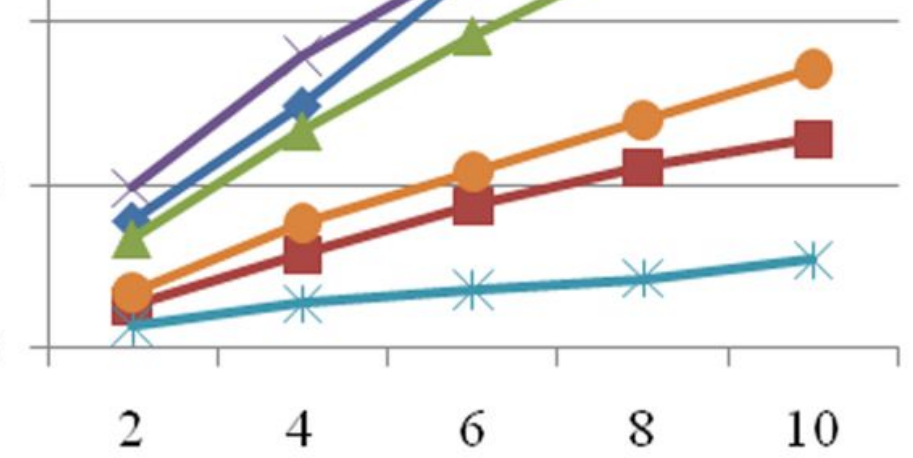

- $100 \%$ vinegar

- blank control

Time (h)

Figure 9

Permeation profiles of palmatine hydrochloride in plasters containing transdermal promoter with best skin penetration effects in their respective series 

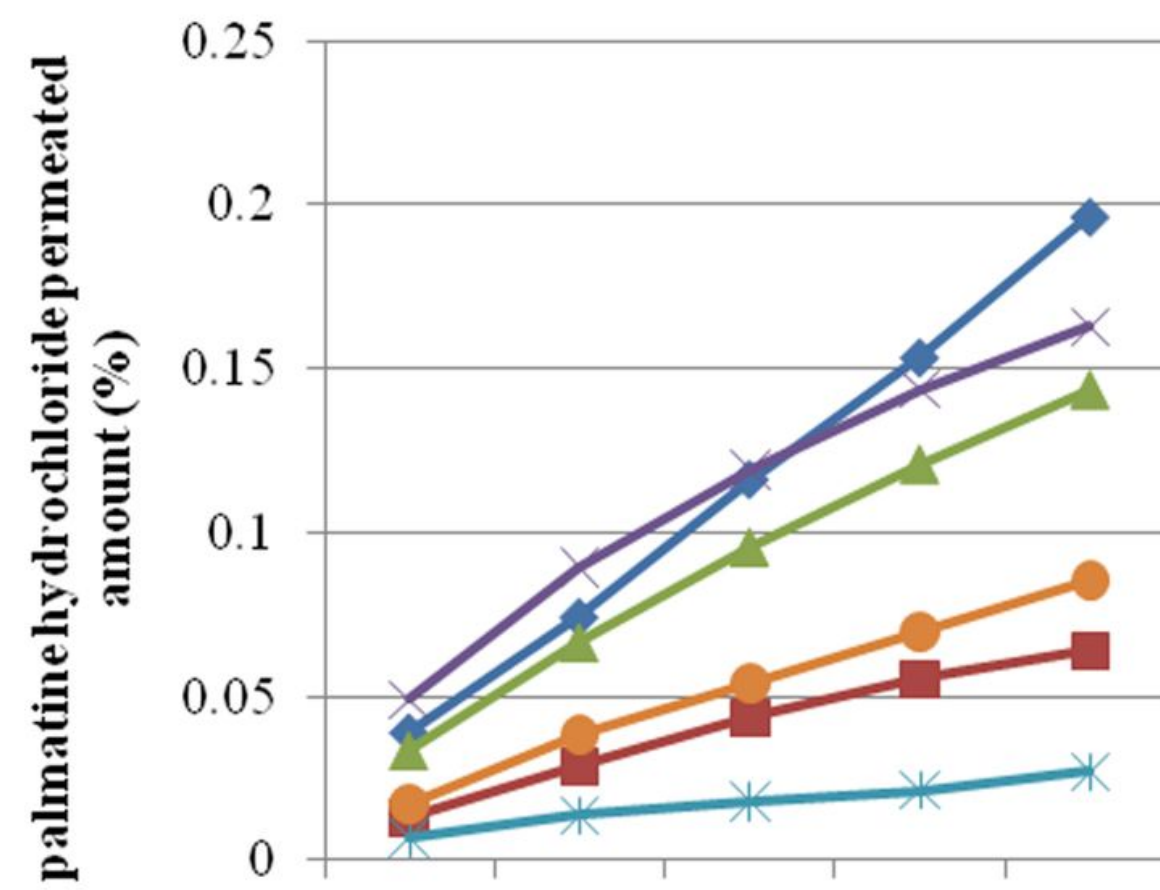

$-45 \%$ acetic acid

$-50 \%$ dimethyl sulfoxide

$-1 \%$ water-soluble azone

$\leftarrow 5 \%$ fat-soluble azone

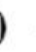

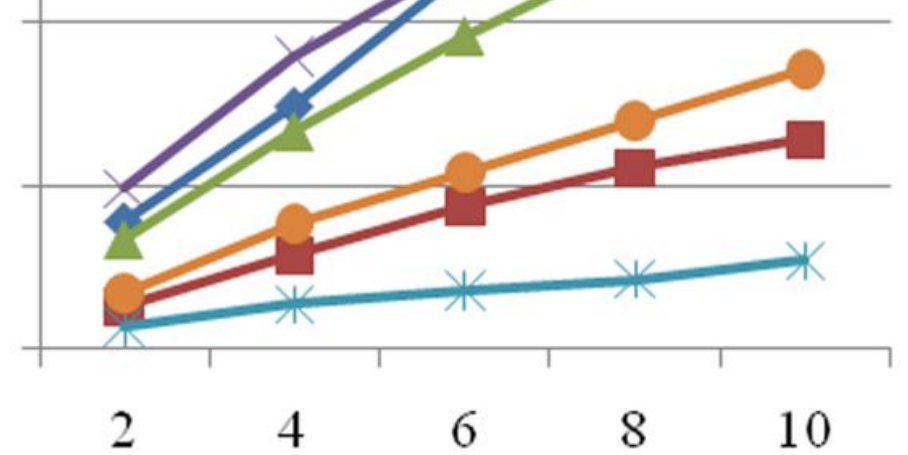

* $100 \%$ vinegar

- blank control

Time (h)

Figure 9

Permeation profiles of palmatine hydrochloride in plasters containing transdermal promoter with best skin penetration effects in their respective series 

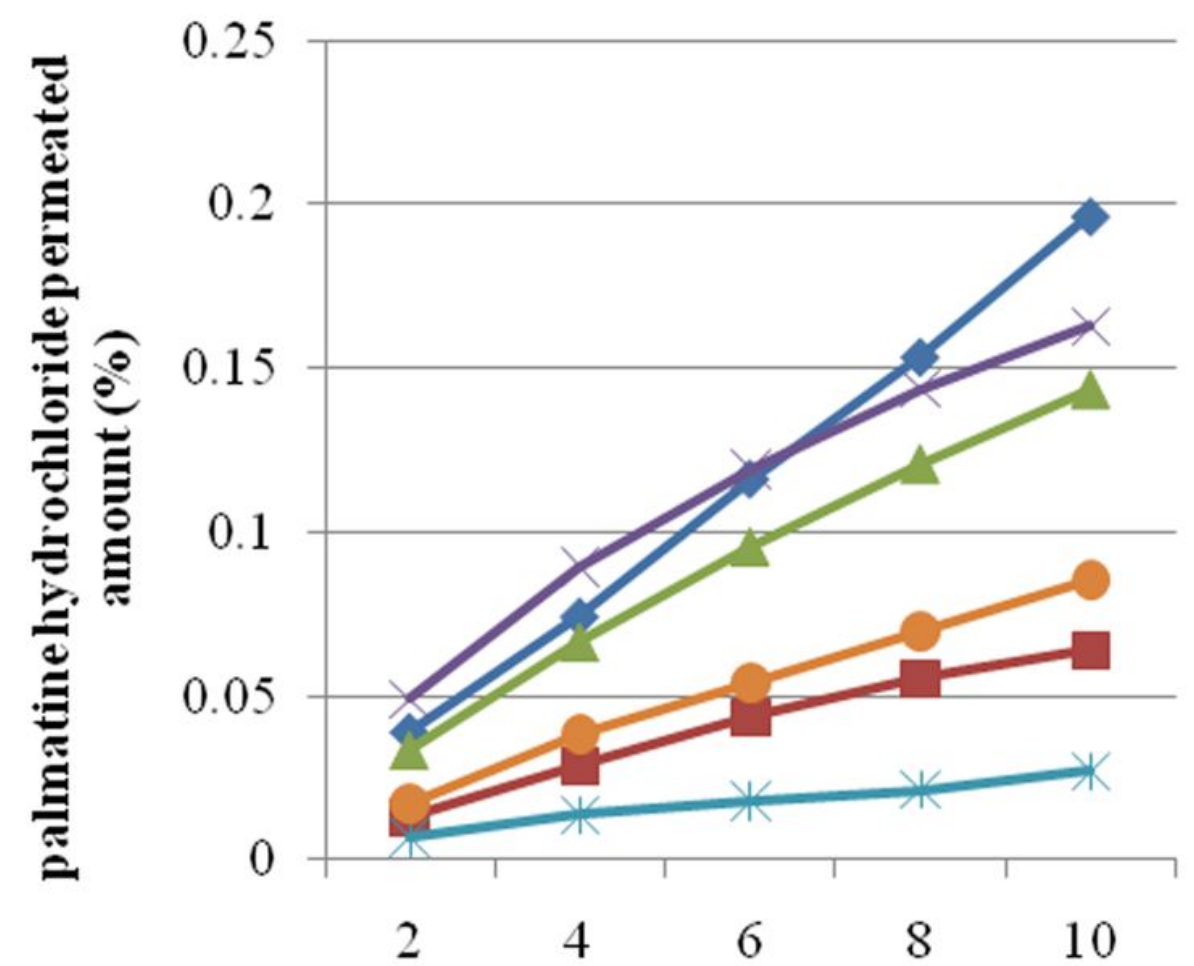

$-45 \%$ acetic acid

$-50 \%$ dimethyl sulfoxide

$-1 \%$ water-soluble azone

$\longleftarrow 5 \%$ fat-soluble azone

ㄴ $100 \%$ vinegar

- blank control

Time (h)

Figure 9

Permeation profiles of palmatine hydrochloride in plasters containing transdermal promoter with best skin penetration effects in their respective series 


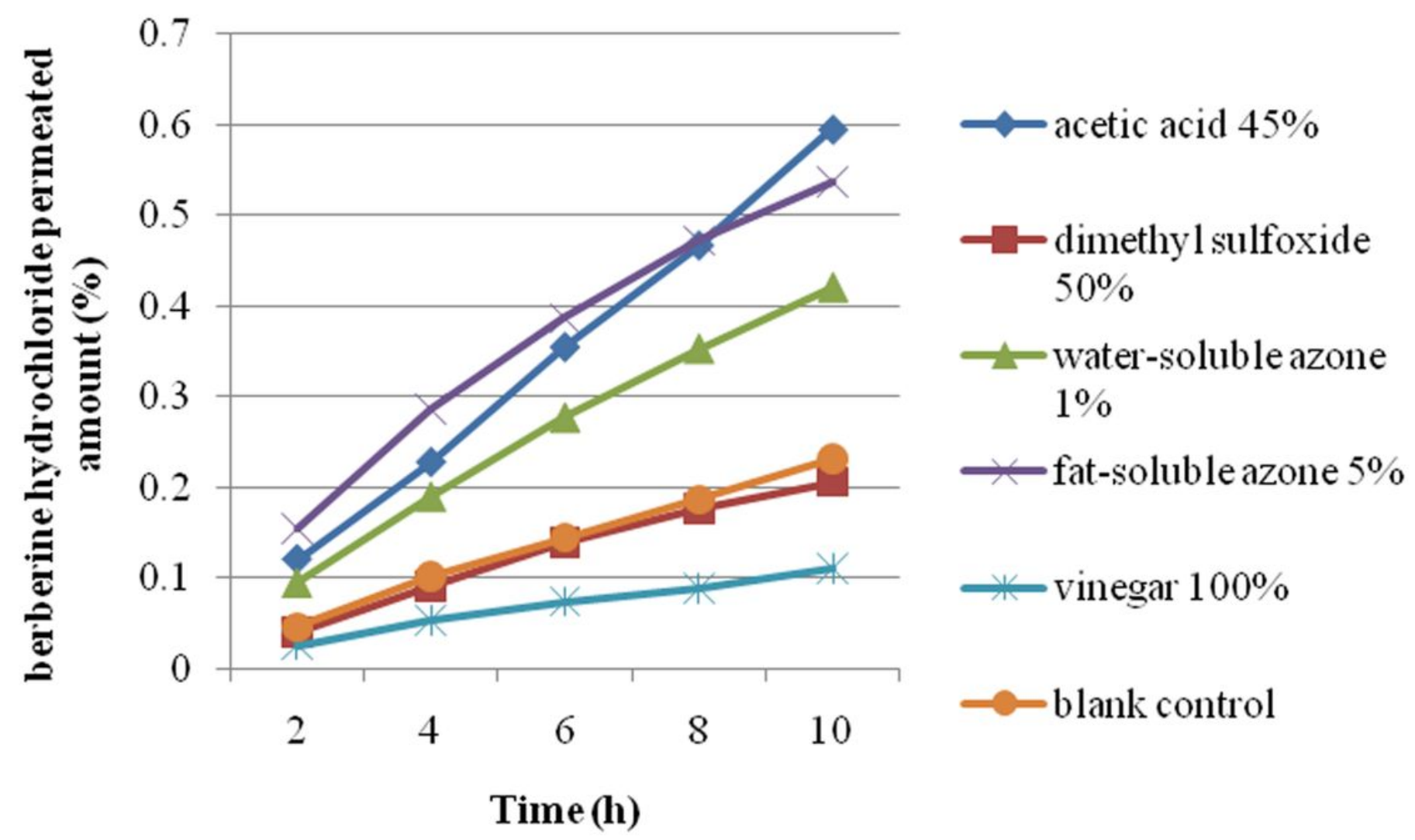

Figure 10

Permeation profiles of berberine hydrochloride in plasters containing transdermal promoter with best skin penetration effects in their respective series 


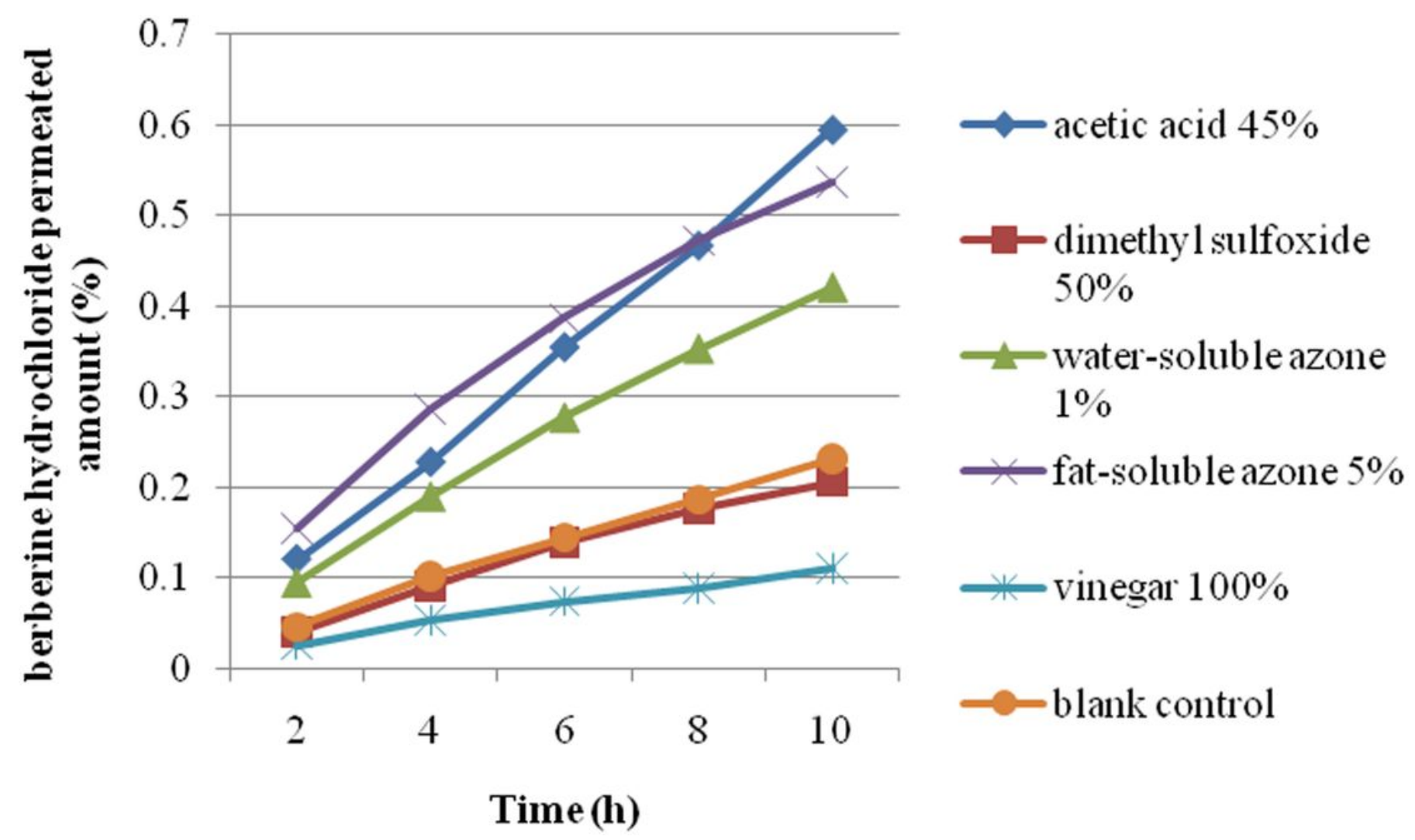

Figure 10

Permeation profiles of berberine hydrochloride in plasters containing transdermal promoter with best skin penetration effects in their respective series 


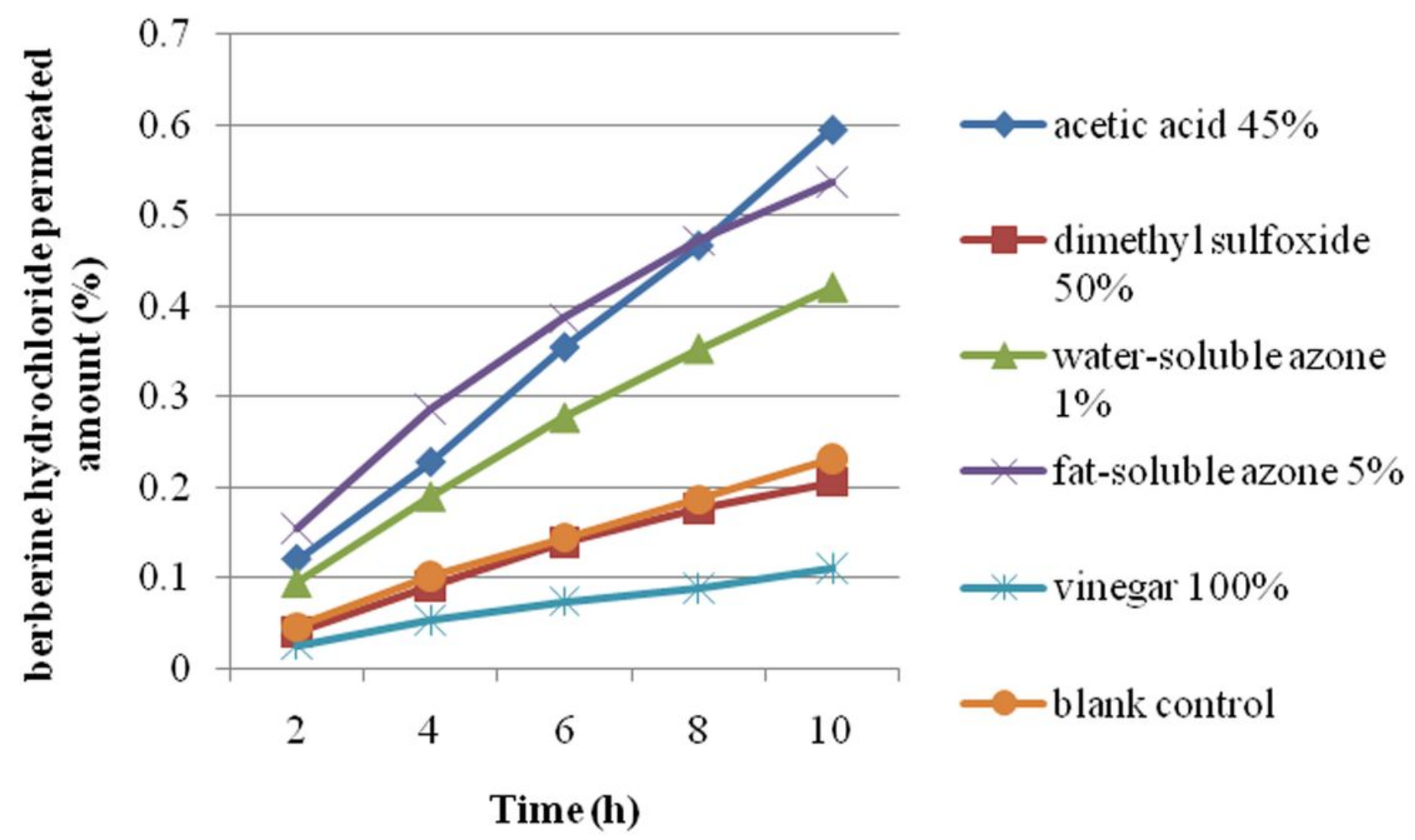

Figure 10

Permeation profiles of berberine hydrochloride in plasters containing transdermal promoter with best skin penetration effects in their respective series 


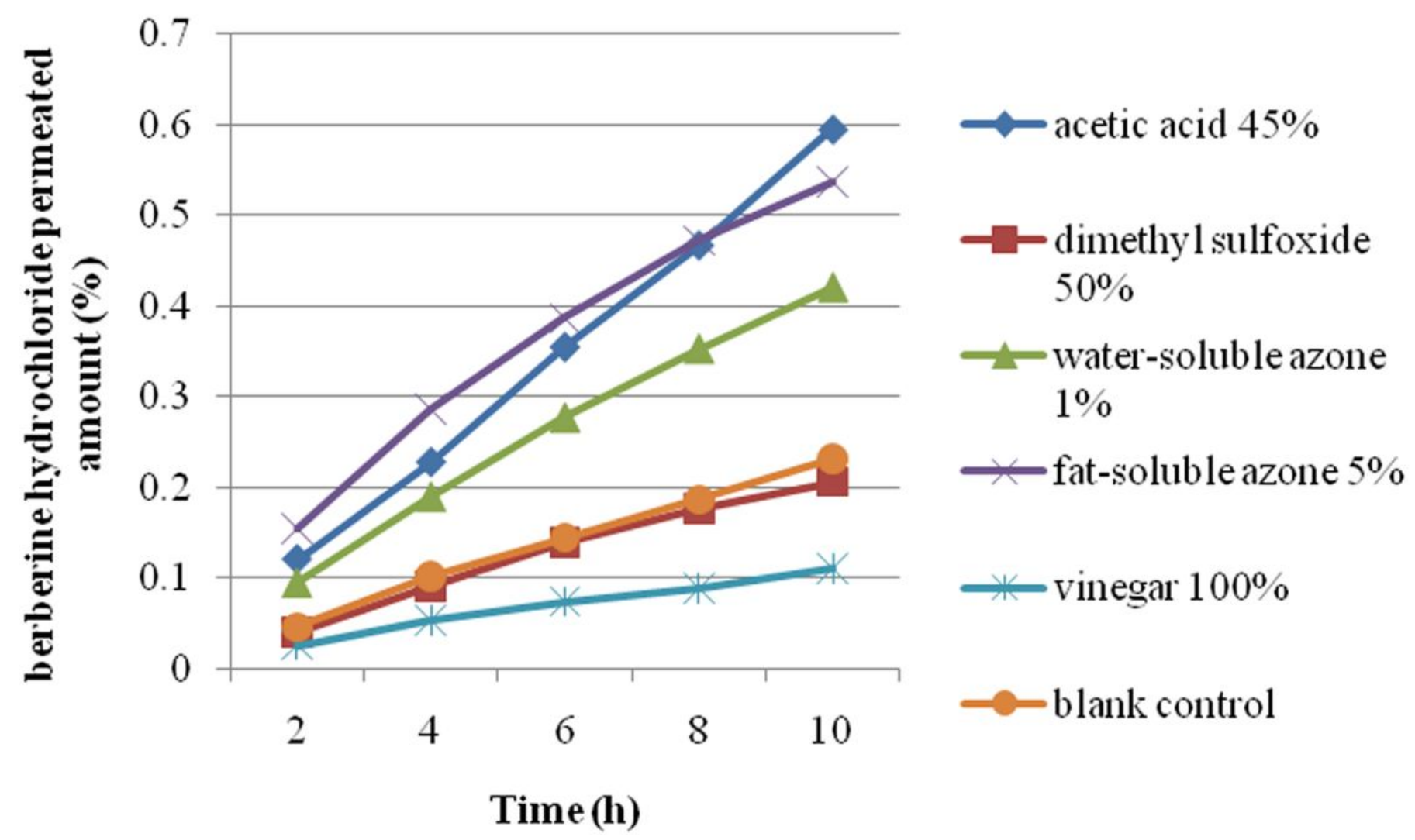

Figure 10

Permeation profiles of berberine hydrochloride in plasters containing transdermal promoter with best skin penetration effects in their respective series 